\title{
Review Article \\ New Pathogenic Concepts and Therapeutic Approaches to Oxidative Stress in Chronic Kidney Disease
}

\author{
José Pedraza-Chaverri, ${ }^{1}$ Laura G. Sánchez-Lozada, ${ }^{2,3}$ \\ Horacio Osorio-Alonso, ${ }^{2,3}$ Edilia Tapia, ${ }^{2,3}$ and Alexandra Scholze ${ }^{4,5}$ \\ ${ }^{1}$ Department of Biology, Faculty of Chemistry, UNAM, 04510 Mexico City, DF, Mexico \\ ${ }^{2}$ Laboratory of Renal Physiopathology, INC Ignacio Chávez, 14080 Mexico City, DF, Mexico \\ ${ }^{3}$ Department of Nephrology, INC Ignacio Chávez, 14080 Mexico City, DF, Mexico \\ ${ }^{4}$ Department of Nephrology, Odense University Hospital, 5000 Odense, Denmark \\ ${ }^{5}$ Institute of Clinical Research, University of Southern Denmark, 5000 Odense, Denmark
}

Correspondence should be addressed to Alexandra Scholze; ascholze@health.sdu.dk

Received 11 March 2016; Revised 16 May 2016; Accepted 25 May 2016

Academic Editor: Gabriele Saretzki

Copyright (C) 2016 José Pedraza-Chaverri et al. This is an open access article distributed under the Creative Commons Attribution License, which permits unrestricted use, distribution, and reproduction in any medium, provided the original work is properly cited.

In chronic kidney disease inflammatory processes and stimulation of immune cells result in overproduction of free radicals. In combination with a reduced antioxidant capacity this causes oxidative stress. This review focuses on current pathogenic concepts of oxidative stress for the decline of kidney function and development of cardiovascular complications. We discuss the impact of mitochondrial alterations and dysfunction, a pathogenic role for hyperuricemia, and disturbances of vitamin D metabolism and signal transduction. Recent antioxidant therapy options including the use of vitamin D and pharmacologic therapies for hyperuricemia are discussed. Finally, we review some new therapy options in diabetic nephropathy including antidiabetic agents (noninsulin dependent), plant antioxidants, and food components as alternative antioxidant therapies.

\section{Introduction}

In chronic kidney disease both chronic and recurring acute inflammation are frequent. Underlying diseases, like autoimmune diseases, medication, uremic toxins, infections, and hemodialysis therapy are causal. The immune cells involved in those inflammatory processes produce free radicals in form of reactive nitrogen and reactive oxygen species. Overall, an imbalance between those free radicals and the available antioxidant capacity exists in chronic kidney disease (for review see Small et al., 2012, and Tucker et al., 2015, [1, $2])$. Chronic kidney disease (CKD) denotes the presence of structural and/or functional abnormalities of the kidneys, with or without a reduction in glomerular filtration rate, with implications for health, lasting for more than three months [3]. The global prevalence of CKD in adults over 20 years of age was around $10 \%$ in men and $12 \%$ in women in a recent analysis [4]. The causes underlying CKD in a given population differ depending on ethnicity, region $[5,6]$, and age [7]. In children, congenital and hereditary disorders predominate. To this group belong cystic kidney diseases and obstructive uropathy. In adults, for example, in the United States the leading causes for CKD resulting in end-stage renal disease are diabetic nephropathy (type 2 diabetes mellitus accounts for around 30\%, type 1 for around 6\%), vascular diseases (like hypertension and ischemic renal disease) accounting for around 25\%, glomerular diseases (including focal segmental glomerulosclerosis) accounting for around $18 \%$, renal carcinoma, cystic diseases and tubulointerstitial disease [8].

$\mathrm{CKD}$ is characterized by a gradual loss of kidney function. It progresses through an initial lesion, the occurrence of repair mechanisms in which nephrons are lost, and the increase of activity of remaining nephrons that may be detrimental for nephron function. This disturbance frequently shows a pattern characterized by reduced glomerular filtration, disturbed salt and water balance, and loss of endocrine functions [9]. The development of fibrosis in the glomeruli 
and in the tubulointerstitial space is considered as common pathological alteration in CKD [10].

CKD is significantly linked to premature cardiovascular disease development. At the same time, cardiovascular disease (CVD) is the most common cause of death in CKD [11$13]$.

Underlying mechanisms comprise traditional cardiovascular risk factors that are common also in CKD patients like advanced age, hypertension, and diabetes mellitus. But since those traditional risk factors do not sufficiently account for the high cardiovascular risk in CKD CKD-associated risk factors have received much attention. The latter include malnutrition, inflammation, uremic toxins, proteinuria, bone and mineral metabolism abnormalities, persistent neurohormonal activation, and oxidative stress [14-16]. Currently, the following oxidative stress related mechanisms are thought to be especially important for the pathogenesis of CVD in CKD: protein-bound uremic toxins initiating oxidative stress-inflammation-fibrosis processes $[16,17]$, advanced glycation end products resulting in receptor-mediated and receptor-independent increase of oxidative stress, inflammation and vascular damage [18], chronic activation of the renin-angiotensin-aldosterone and sympathetic nervous system resulting in, also, oxidative stress-inflammation-fibrosis processes [19], and activation of the innate immune system leading to microinflammation and vascular dysfunction [20]. Mitochondrial dysfunction, causing increased oxidative stress and ATP depletion, is gaining attention in CKD and is discussed more in depth further down in this review.

Systemic oxidative stress is proposed to play a central role not only in the pathogenesis of CVD but also in kidney function decline and premature aging in CKD. Recent excellent reviews provided detailed overview over the current knowledge about the underlying molecular mechanisms and possible therapeutic interventions [21-23]. Especially in end-stage renal disease evidence-based therapeutic strategies to improve survival are limited (for review see [24]). The latest Cochrane review about "antioxidants for chronic kidney disease" in 2012 stated that "antioxidant therapy in CKD does not reduce the risk of cardiovascular and allcause death" but "it is possible that some benefit may be present, particularly in those on dialysis" [25]. Antioxidant interventions in CKD, employing either antioxidant substances, substances that possess antioxidant effects among their mechanisms of action, or lifestyle interventions have been reviewed in depths recently: bardoxolone methyl [26], $\mathrm{N}$-acetylcysteine [27, 28], vitamin E [27, 29], statins [30], renin-angiotensin-aldosterone system interventions [19, 31], interventions targeting gut-derived endotoxins and uremic toxins [16, 32, 33], and exercise training [34]. Selected substances and interventions with mechanistic and clinical information are given as supplementary material (see Supplementary Table 1 in Supplementary Material available online at http://dx.doi.org/10.1155/2016/6043601).

Nevertheless, the causal connection of oxidative stress to the genesis of cardiovascular disease in chronic kidney disease has also been controversially discussed $[35,36]$. Those discussions were based on the one hand on the inconclusive results concerning the connection between supposed markers of oxidative stress and cardiovascular events and mortality in clinical studies $[35,36]$. On the other hand, the up to date limited success of antioxidant therapies on cardiovascular outcomes in CKD patients but also in other populations demands a more differentiated view on oxidative stress-related pathogenic concepts and asks for new therapeutic approaches [37].

Our review therefore focuses on selected recent aspects in the discussion of pathogenic concepts and therapeutic approaches to oxidative stress in chronic kidney disease.

\section{Mitochondrial Alterations in Chronic Kidney Injury and CKD}

2.1. Mitochondrial Alterations in Chronic Kidney Injury. Reactive oxygen species (ROS) production has been clearly associated with the development of CKD and mitochondria are among the major ROS sources in renal diseases (reviewed in [38]). In fact, it has been found in several studies that oxidative stress in CKD patients enhances as the disease progresses [39-41]. Mitochondria are important in mammalian cells since these organelles supply all the necessary biological energy derived from the breakdown of carbohydrates and fatty acids, which is converted to adenosine triphosphate (ATP) via the process of oxidative phosphorylation. However, mitochondria also participate in cellular mechanisms associated with cell damage and cell death signaling [42-44]. The high energy demands of the kidney and other organs as brain and heart depend heavily on functional mitochondria. The kidney cells, particularly the mitochondria-rich proximal tubule epithelial cells, have high ATP requirements to facilitate active reabsorption of macromolecules [45-47]. About $80 \%$ of the oxygen consumed for ATP production supports active sodium transport while the basal metabolic rate accounts for only 15$20 \%$ of the oxygen consumption rate [48]. Mitochondrial content is closely regulated by mitochondrial biogenesis (the increase in the number of preexisting mitochondria) and mitophagy (the removal of damaged or dysfunctional mitochondria through autophagy). Both processes act to maintain mitochondrial homeostasis since mitochondrial biogenesis increases net mitochondrial mass to preserve mitochondrial functions by compensating for loss of damaged mitochondria by mitophagy [49-51]. Although mitochondria have their own DNA (mtDNA) most of the proteins that localize in mitochondrial membranes are nuclear gene products. Mitochondrial biogenesis involves the coordinated participation and expression of the genes localized in mitochondria and nuclei. Nuclear respiratory factors 1 and 2 (NRF1 and NRF2) are nuclear-encoded transcription factors that act on the nuclear genes coding for constituent subunits of the oxidative phosphorylation system and also regulate the expression of many other genes involved in mtDNA replication [52].

Peroxisome proliferator-activated receptor gamma $(\mathrm{PPAR} \gamma)$ coactivator- 1 alpha (PGC- $1 \alpha)$ is a nuclear-encoded transcriptional coactivator that regulates the expression of nuclear-encoded mitochondrial proteins, including NRF1 and NRF2 [51, 53]. PGC- $1 \alpha$ is predominantly expressed 
TABLE 1: Markers used to evaluate mitochondrial biogenesis, mitochondrial dynamics, and mitophagy.

\begin{tabular}{|c|c|c|}
\hline Mechanism & Marker & Function (site) \\
\hline \multirow{4}{*}{$\begin{array}{l}\text { Mitochondrial } \\
\text { biogenesis }\end{array}$} & $\begin{array}{l}\text { Subunit } 1 \text { of mitochondrial NADH dehydrogenase } \\
\text { mitochondrial (MT-ND1). }\end{array}$ & $\begin{array}{l}\text { Subunit of NADH dehydrogenase (mitochondrial inner } \\
\text { membrane). }\end{array}$ \\
\hline & Mitochondrial transcription factor A (TFAM). & $\begin{array}{l}\text { Activator of mitochondrial transcription } \\
\text { (mitochondria). }\end{array}$ \\
\hline & $\begin{array}{l}\text { Nuclear respiratory factors } 1 \text { and } 2(\mathrm{NRF} 1, \mathrm{NRF} 2) \text { and } \\
\text { estrogen receptor alpha }(\mathrm{ERR} \alpha) .\end{array}$ & $\begin{array}{l}\text { Transcription factors for mitochondrial biogenesis } \\
\text { (nuclei). }\end{array}$ \\
\hline & $\begin{array}{l}\text { Peroxisome proliferator-activated receptor gamma, } \\
\text { coactivator } 1 \text { alpha (beta) }(\mathrm{PGCl} \alpha, \mathrm{PGC} \beta) \text {. }\end{array}$ & $\begin{array}{l}\text { Transcriptional coactivator that regulates the genes } \\
\text { involved in mitochondrial biogenesis (nuclei). }\end{array}$ \\
\hline \multirow{3}{*}{$\begin{array}{l}\text { Mitochondrial } \\
\text { dynamics }\end{array}$} & $\begin{array}{l}\text { Dynamin related protein } 1 \text { (Drp-1). } \\
\text { Mitochondrial fission protein } 1 \text { (Fis1). }\end{array}$ & Mitochondrial fission. \\
\hline & Sirtuin 3 (SIRT3). & Decreases mitochondrial fission. \\
\hline & $\begin{array}{l}\text { Optic atrophy } 1 \text { protein (OPA1). } \\
\text { Mitofusin-1 (Mfn1) protein. } \\
\text { Mitofusin-2 (Mfn2) protein. }\end{array}$ & Mitochondrial fusion. \\
\hline \multirow{4}{*}{ Mitophagy } & Pten-induced kinase 1 (PINK1). & $\begin{array}{l}\text { PINK1 activity causes the parkin protein to bind to } \\
\text { depolarized mitochondria to induce autophagy. }\end{array}$ \\
\hline & Parkin protein. & Mediates the targeting of proteins for degradation. \\
\hline & Mitochondrial E3. Ubiquitin ligase 1 (Mul1). & Activator of mitophagy. \\
\hline & FoxO1/FoxO3 transcription factors. & Activators of mitophagy. \\
\hline
\end{tabular}

in proximal tubules, indicating the effectiveness of PGC$1 \alpha$ in proximal tubular homeostasis [54]. Enforced overexpression of PGC- $1 \alpha$ in cultured proximal tubular cells increased mitochondrial number, respiratory capacity, ATP concentration, and mitochondrial proteins [55].

Autophagy, derived from the Greek word meaning "selfeating," is a catabolic pathway involving the degradation of cellular components by the hydrolases of lysosomes to maintain homeostasis and cell integrity [56, 57]. Dysregulated autophagy has been linked to many human pathophysiologies. Accumulating body of evidence implicates that autophagy regulates many critical aspects of normal and disease conditions in the kidney $[44,58]$.

Imbalance between mitochondrial biogenesis and the mitophagy process results in progressive development of numerous pathologic conditions associated with mitochondrial dysfunction characterized by the increase of mitochondrial ROS production, mitochondrial permeability transition (MPT) pore opening, and apoptosis $[44,59,60]$.

It has been widely demonstrated that mitochondrial morphology plays an important role in cellular functions and that it is affected by the occurrence and rates of fission and fusion events [61]. Fission is the division of mitochondria within a cell to form separate mitochondrial compartments, while fusion is the merging of two or more mitochondria to form a single compartment. Dynamin-related protein (Drp-1) and mitochondrial fission protein 1 (Fisl) promote mitochondrial fission to create new mitochondria and to remove damaged mitochondria when cells are under stress $[62,63]$. Mitochondrial fusion involves fusion of both the outer mitochondrial membrane and inner mitochondrial membrane, a process depending on mitofusin-1 (Mfn1), mitofusin-2 (Mfn2), and OPA1 (a dynamin-related protein with GTPase activity) [64]. It has been observed that defects in these proteins are closely related with alterations in both mitochondrial function and shape and as a consequence are associated with human diseases. For example, loss of function with Mfn2 mutation is related to Charcot-Marie-Tooth disease type $2 \mathrm{~A}$ while OPA1 mutation is related to optic atrophy [65]. Until recently it has been appreciated that the equilibrium between fission and fusion events is important for mitochondrial function and distribution and, therefore, is pivotal for cell survival and health of the organism. Disturbances on this balance have a fundamental role in mitochondrial fragmentation and dysfunction [44, 65] and have been involved in a number of biological processes including cell division, apoptosis, autophagy, and metabolism. During cell injury, the equilibrium between mitochondrial fusion and fission shifts to mitochondrial fission and mitochondrial fragmentation occurs. This results in alterations in mitochondrial structure and morphology [66]. These changes might thereby contribute to kidney disease $[67,68]$. Table 1 shows a list of markers used to evaluate mitochondrial biogenesis, mitochondrial dynamics (fission and fusion), and mitophagy.

2.2. Mitochondrial Alterations in CKD. Kidney cells contain abundant mitochondria, therefore mitochondrial dysfunction has a fundamental role in the development of kidney diseases. Many reports indicate the role of mitochondria in progression of CKD (reviewed in [69]). In the rat model of 5/6 nephrectomy Nath et al. [70] reported an increase in the rate of oxygen consumption in surviving nephrons and Fedorova et al. [71] observed in renal cortex of the same model a decrease in the expression in medium-chain acyl-coenzyme A dehydrogenase (MCAD) and cytochrome c oxidase subunit IV (COXIV) proteins as well as in the copy number of mtDNA. Sun et al. [72], using electron microscopy 
and confocal microscopy, reported alterations in mitochondrial structure and mitochondrial fragmentation in apoptotic tubular cells in kidneys from diabetic mice. Additionally, they reported cytochrome $\mathrm{c}$ release associated with apoptotic processes in tubular cells exposed to high glucose. These data reveal an association between mitochondrial dynamics and apoptosis in the progression of diabetic nephropathy. In fact, it is well known that oxidative stress induces apoptosis, a key process for the loss of functional tissue in CKD (reviewed in [1]). In this context, Daehn et al. [73] showed that apoptosis of podocytes in mice with glomeruloesclerosis secondary to adriamycin was associated with mitochondrial oxidative stress. Scavenging of ROS-derived mitochondria was able to protect podocytes and prevent renal failure and glomerulosclerosis. Furthermore, Chen et al. [74] showed that the protective effect of the antifibrotic drug pirfenidone of tubulointerstitial damage in 5/6 nephrectomized rats was associated with prevention of mitochondrial damage and with the decrease in tubular cell apoptosis and oxidative stress.

On the other hand, Wang et al. [75] found mitochondrial fission and fragmentation in renal cells in a conditional gene knock-out and knock-in mouse model in response to Drp1 phosphorylation and activation by Rho-associated coiled coil-containing protein kinase 1 (ROCK1). Mitochondrial cytopathies (MC) are inherited mtDNA or nuclear DNA (nDNA) mutations in genes that affect mitochondrial functions. A single cell contains hundreds of mtDNA copies and, therefore, as a consequence of fission and fusion processes, the normal mtDNA may mix with mutant mtDNA. When the amount of mutant mtDNA copies surpasses the basal level a cell dysfunction occurs [69]. These alterations in kidneys result in focal segmental glomerular sclerosis (FSGS), tubular defects [69], cystic kidney disease [76-78], and renal carcinoma $[79,80]$.

Genetic defects connected to renal diseases include tRNA-LEU mutations (e.g., 3,243 A $>\mathrm{G}$ point mutation). So, in coenzyme Q10 (CoQ10) deficiency mutations of COQ1PDSS2, COQ2, COQ6, and COQ9 have been reported. For impaired complex III assembly a mutation in BCS1L has been described and also a mutation in COX10 was reported leading to complex IV inactivation [69]. Mitochondria are also involved in epithelial to mesenchymal transition of renal tubular epithelial cells, a phenotypic conversion that contributes to the pathogenesis of renal interstitial fibrosis $[69,81]$. Renal biopsies from patients showing simultaneously mitochondrial myopathy, encephalopathy, lactic acidosis, and stroke-like episodes (MELAS) syndrome and FSGS often show dysmorphic mitochondria in podocytes (epithelial cells with interdigitated foot processes that surround the glomerular capillaries) and effacement of podocyte foot processes.

Based on the fact that mtDNA mutations in podocytes were associated with FSGS in two children, Güçer et al. [82] postulated that podocytes with atypical mitochondria have a role in the development of glomerular diseases. FSGS is associated with genetic alterations and is characterized by altered mitochondria in podocytes and podocytes effacement [69]. Studies in mice subjected to aldosterone-induced renal injury show a decrease in mtDNA copy number, loss of mitochondrial membrane potential $\left(\Delta \psi_{\mathrm{m}}\right)$, drop of ATP production, and oxidative stress $[83,84]$. These changes occur before proteinuria and podocyte process fusion can be observed. Podocyte foot process effacement also has been observed under high glucose conditions, probably through phosphorylation of Drp-1 by ROCK1 [75]. Mitochondrial alterations are also observed in arteriolar hyalinosis [85] as well as in steroid-resistant nephrotic syndrome [86]. So, it is clear that alterations in mtDNA may induce alterations in microvasculature and in podocytes, which are fatal insults to the kidney. Studies in peripheral blood mononuclear cells of CKD patients receiving peritoneal dialysis show decreased expression of NRF1 and PGC1- $\alpha$ and of several PGC1- $\alpha$ downstream target genes as mitochondrial transcription factor A (TFAM), cytochrome $\mathrm{c}$ oxidase subunit 6C (COX6C), cytochrome $\mathrm{c}$ oxidase subunit $7 \mathrm{C}$ (COX7C), mitochondrial Hinge protein ubiquinol-cytochrome $\mathrm{C}$ reductase Hinge gene (UQCRH), and MCAD [87]. In addition, Dugan et al. [88] found decreased protein and mRNA levels of PGCl $\alpha$ in kidneys of diabetic mice, which were prevented by the treatment of mice with the adenosine monophosphate-activated protein kinase (AMPK) activator 5-aminoimidazole-4-carboxamide$1-\beta$-D-ribofuranoside (AICAR). Moreover, Granata et al. [89] reported an increase in ROS production, DNA oxidative damage and mitochondrial cytochrome $\mathrm{c}$ oxidase subunit 1 (COX1) expression, upregulation of 11 genes related to the oxidative phosphorylation system (ATP50, ATP51, and ATP5J: components of the ATP synthase complex V, NDUFS5, NDUFA6, NDUFA1, and NDUFB1: subunits of mitochondrial complex I, COX6C/COX7C: subunits of mitochondrial complex IV, and UQCRH and UQCRB: subunits of mitochondrial complex III), and a decrease in complex IV activity in peripheral blood mononuclear cells of CKD patients receiving hemodialysis. Granata et al. [89] concluded that CKD patients receiving hemodialysis had an impaired mitochondrial respiratory system.

The mitochondrial function at different stages of CKD remains to be fully studied. It has been found that, at early stages of 5/6 nephrectomy $(24 \mathrm{~h})$, renal dysfunction and mitochondrial oxidative stress are associated with decreased mitochondrial adenosine diphosphate induced respiration and low activity of respiratory complexes I and V. The mitochondrial alterations were prevented by the administration of the antioxidant curcumin [Aparicio-Trejo et al., manuscript submitted]. In contrast, it has been found on day 30 after $5 / 6$ nephrectomy that renal mitochondrial bioenergetics was unaltered [90]. These data suggest that mitochondrial alterations are not similar along the development of CKD.

Many evidences indicate that mitochondrial dysfunction may be involved in the pathophysiology of kidney diseases although the mechanism responsible for the changes of mitochondrial dynamics under disease conditions is largely unknown. Future experiments should be directed to unravel these mechanisms as well as to design strategies to attenuate renal diseases using as a target the attenuation of mitochondrial alterations [91]. In addition, more studies are needed to evaluate the time-course changes of mitochondrial parameters along the development of CKD to establish the kinetic of these changes. 


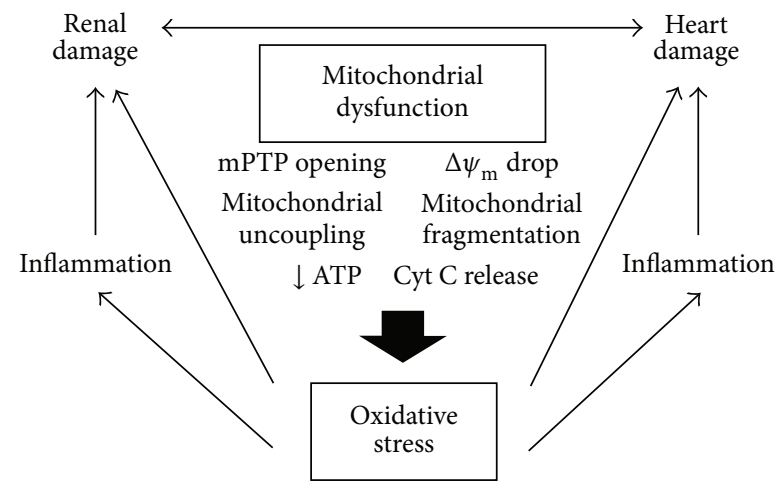

FIGURE 1: Integrative scheme of the mechanisms that cause kidney and heart damage secondary to mitochondrial dysfunction. Mitochondrial dysfunction represented by mitochondrial permeability transition pore opening, mitochondrial uncoupling/fragmentation, mitochondrial membrane potential loss, cytochrome $\mathrm{C}$ release, and decreased ATP synthesis, among other mitochondrial alterations, causes oxidative stress that leads to inflammatory state. Both conditions result in renal and cardiac damage that often occurs at the same time and establishes a intercommunication through hemodynamic and nonhemodynamic mechanisms.

2.3. Cardiovascular Disease, Oxidative Stress, and Mitochondrial Deregulation. Mitochondrial alterations also have been found in hearts when renal function declines (Figure 1). Using an experimental model of cardiorenal syndrome, Sumida et al. [92] reported mitochondrial fragmentation, increased dynamin-related protein 1 (DRP-1) expression, apoptosis, and cardiomyocyte dysfunction in hearts of mice subjected to bilateral renal ischemia reperfusion. The inhibition of DRP-1 attenuated significantly the changes observed in the heart. The study of Hernández-Reséndiz et al. [93] is another example of interrelation between kidney and heart. Rats with 5/6 nephrectomy exhibited elevated systolic blood pressure, proteinuria, cardiac dysfunction, oxidative stress, activation of apoptotic mitochondrial pathway, and alterations in cardiac mitochondrial integrity (inability to retain calcium and fall in transmembrane potential). All these cardiac, systemic, and mitochondrial alterations were prevented by the administration of curcumin. Moreover, Taylor et al. [94] also demonstrated a cross-talk between the kidneys and the heart using the 5/6 nephrectomy model in rats. They found that state 4 respiration was enhanced. In addition, after ischemia reperfusion uremic mitochondria showed a significant increase in state 4 respiration and reduction in respiratory control ratio and uremic cardiomyocytes were more vulnerable to $\mathrm{H}_{2} \mathrm{O}_{2}$-induced stress.

\section{Hyperuricemia, Oxidative Stress, and CKD}

Uric acid is the product of purine metabolism in primates including man and is an essential antioxidant for these organisms, for they have lost uricase activity during evolution. It has been suggested that this particular antioxidant system could have replaced the lost capability for vitamin $\mathrm{C}$ synthesis, therefore, allowing humans to evolve as uric acid increased longevity [95] and provided neuroprotection [96]. Due to the similarity of uric acid to the caffeine molecule, that characteristic also enabled it to act as a mental stimulant [97], therefore, providing an advantage for the development of human intelligence. Another benefit of an increased concentration of uric acid in humans is that it stimulates the activity of the renin-angiotensin system. This effect facilitated the maintenance of blood pressure during the evolution to bipedalism under the low sodium diets, prevalent during human evolution [98]. Humans are prone to conserve uric acid, and its renal excretion is limited to $8-10 \%$ of the filtered load. Like other antioxidants, uric acid may assume prooxidant roles [99] and this effect could partially explain why epidemiologic studies have associated hyperuricemia with hypertension, metabolic syndrome, and chronic kidney disease [100-106].

Hyperuricemia has been arbitrarily defined in men $>7 \mathrm{mg} / \mathrm{dL}$ and in premenopausal women $>6.5 \mathrm{mg} / \mathrm{dL}$. However, serum uric acid concentrations are greatly influenced by diet, mainly by red meat, seafood, alcohol, and fructose consumption. Therefore, as these dietary items became more affordable for the general population, the concentrations of uric acid "considered" normal have been progressively increasing from the beginning of the twentieth century [107].

Despite its described role as an antioxidant, the first response to uric acid exposure is a rapidly increase in oxidative stress in endothelial cells, proximal tubule epithelial cells, mesangial cells, vascular smooth muscle cells, hepatocytes, and adipocytes [108-115]. Although the effect of hyperuricemia on renal podocytes has not been directly addressed it is likely that uric acid may have effects on these cells similar to other renal cell types, such as the activation of NALP3 inflammasome [116] and NOX-4 [117]. These studies showed that it is the uric acid which enters into cells that is responsible for increasing intracellular oxidative stress through a mechanism that includes the activation of NADPH oxidase [118]. Interestingly, some of the deleterious effects induced by hyperuricemia are similar to those associated with increased oxidative stress such as reduced nitric oxide bioavailability and endothelial dysfunction, vascular hypertrophy, and inflammation and activation of the renin-angiotensin system [119]. The harmful effects of mild hyperuricemia on kidney function have been documented. Hyperuricemic nephropathy is induced in the laboratory rat by the inhibition of liver uricase. This maneuver induced hypertension, renal vasoconstriction, glomerular hypertension, arteriolopathy, tubulointerstitial fibrosis, and inflammatory infiltration. In this model, the renal and vascular damage was mediated by soluble uric acid, in contrast to gouty nephropathy which is mediated by uric acid crystal deposition [120]. The role of oxidative stress as pathogenic mechanism induced by uric acid was further documented, for the treatment of hyperuricemic rats with an antioxidant prevented hypertension as well as the renal functional and structural alterations induced by hyperuricemia [117]. In addition, deposition of uric acid crystals in proximal tubule cells is also associated with increased oxidative stress and activation of the NRLP3 inflammasome [116]. 
Since hyperuricemia strongly correlates with other metabolic factors (obesity, dyslipidemia, and insulin resistance) its role as a true cardiovascular risk factor in healthy individuals is still under discussion [121]. But increased serum uric acid levels have been found to be an independent risk factor for hypertension, diabetes, chronic kidney disease, and congestive heart failure; moreover, hyperuricemia has a predictive value for the development of vascular and kidney disease in these conditions [122-125].

In CKD patients, a 6-year follow-up found that hyperuricemia showed a J-shaped independent association with all-cause mortality; therefore both abnormally low and high levels of serum uric acid increased the mortality risk [126]. Interestingly, low concentration of serum uric acid is a consequence of malnutrition and high comorbidity burden; this suggests that systemic oxidative stress may be a causative factor for increasing the mortality in these patients [127]. In hyperuricemic hemodialysis patients, reduction of serum uric acid with febuxostat decreased oxidative stress and improved endothelial dysfunction [128].

Hyperuricemia increases as GFR declines in CKD patients. Moreover, gout increases the risk of cardiovascular events and all-cause mortality in hemodialysis patients [129]. Interestingly, it was shown in renal biopsies of CKD patients that hyperuricemia was associated with vascular alterations consistent with arteriolopathy, a lesion frequently observed in experimental studies [130]. Nevertheless, some others have reported nonsignificant associations between hyperuricemia and progression of kidney disease [131, 132]. Accordingly, there is an increasing interest in determining the efficacy of treating hyperuricemia in CKD patients. The use of allopurinol, febuxostat, and topiroxostat therapies decreased serum uric acid and slowed the progression of CKD in five small trials [133-137]. As the debate continues about the role of uric acid as a causative factor or only a marker of renal dysfunction [138], the need for clinical studies including a greater number of patients is evident. In this regard, currently a major NIH trial, including six academic centers, is ongoing to determine if lowering uric acid with allopurinol may provide benefit in type 1 diabetic subjects with early evidence of renal disease (PEARL) [139].

Whether hyperuricemia could confer risk for developing $\mathrm{CKD}$ in normal subjects is also a relevant issue. A recent meta-analysis, which included more than 190,000 non-CKD individuals, found that hyperuricemia is an independent predictor for the new-onset of CKD [140]. In addition, the treatment of hyperuricemia provides benefit for controlling risk factors associated with the development of CKD. Thus, in adolescents with early onset of essential hypertension and obese subjects with prehypertension, allopurinol treatment significantly reduced systolic and diastolic blood pressure $[141,142]$.

In conclusion, the role of hyperuricemia as a true risk factor for the development of CKD is still under debate. The discussion is complicated by the fact that the noxious effects of uric acid occur inside the cell; thus, serum uric acid might not fully reflect this phenomenon. More studies to disclose the impact of hyperuricemia in the pathogenesis of CKD are warranted.

\section{Antioxidant Potential of Vitamin $D$ in Chronic Kidney Disease}

Chronic kidney disease (CKD) is accompanied by reduced plasma concentrations of 25-dihydroxyvitamin D and 1,25dihydroxyvitamin $\mathrm{D}$ to varying extent.

Vitamin D is taken up with the diet or produced in the skin after exposure to ultraviolet rays of sunlight [143]. In the liver vitamin $\mathrm{D}$ is hydroxylated to 25-hydroxyvitamin D probably by the cytochrome P-450 CYP2R1 [144]. A further hydroxylation step to 1,25-dihydroxyvitamin D is achieved through 1-alpha-hydroxylase (cytochrome P-450 27B1) activity [145]. This takes place in the kidney and in a multitude of extrarenal cells. Renal 1,25-dihydroxyvitamin $\mathrm{D}$ production mainly serves endocrine purposes like regulation of bone and calcium-phosphate metabolism. Vitamin $\mathrm{D}$ effects on the immune system or cell proliferation are supposed to be mainly due to auto- and paracrine actions of 1,25-dihydroxyvitamin D produced in extrarenal cells [146]. The effects of vitamin D are mediated to a large extent through binding to a nuclear receptor, the vitamin $\mathrm{D}$ receptor [147].

Numerous groups have reported important insights about the connection between the vitamin D receptor and oxidative stress or oxidative damage. In their vitamin $\mathrm{D}$ receptor knock-out model Kállay et al. showed that a significant increase of oxidative DNA damage occurred with complete loss of vitamin D receptor [148]. Aortic smooth muscle cells from vitamin D receptor knock-out mice showed increased NADPH oxidase-dependent superoxide anion production [149]. Interestingly, curcumin that shows a variety of antioxidant effects (for review see [150]) was also shown to be a vitamin $\mathrm{D}$ receptor ligand and increased the expression of vitamin $D$ responsive element containing genes [151, 152].

Another important molecular link between the vitamin D system and oxidative stress or oxidative damage is the alpha klotho protein that was originally identified to be an antiaging factor [153]. The kidney is an important source of circulating alpha klotho and both kidney and circulating alpha klotho amount are reduced in CKD [154-156]. Circulating alpha klotho concentrations can be increased by vitamin $\mathrm{D}$ receptor agonists through vitamin $\mathrm{D}$ receptor-mediated gene expression [154, 157]. Antioxidant effects of alpha klotho have been widely described. Alpha klotho protected lung and lung epithelial cells through increased antioxidant capacity while alpha klotho deficiency in acute kidney injury increased oxidative damage to these cells due to decreased antioxidant capacity $[158,159]$. In aortic smooth muscle cells alpha klotho upregulated antioxidant enzymes and glutathione [160]. In retinal pigment epithelium the production of reactive oxygen species was reduced by alpha klotho [161]. Together, alpha klotho and 1,25-dihydroxyvitamin D promote antioxidation (for review see [162]).

In animal models vitamin $\mathrm{D}$ deficiency resulted in oxidative and nitrosative stress and was suggested to enhance contrast media nephrotoxicity by an oxidative stress-related mechanism [163-165]. In humans with chronic hepatitis vitamin D insufficiency was associated with increased global oxidative stress markers [166]. 
In cell and animal studies protective effects of vitamin $\mathrm{D}$ against oxidative stress or oxidative damage were reported by a multitude of research groups. In skin cells 1,25-dihydroxyvitamin D treatment was able to reduced UVinduced DNA damage [167]. The pretreatment of human umbilical vein endothelial cells with 1,25-dihydroxyvitamin D significantly reduced acetoacetate-induced oxidative stress and inhibited superoxide anion generation [168, 169]. Also, gene ontology analysis of vitamin $\mathrm{D}$ receptor activation in human vascular smooth muscle cells revealed modulation of genes related to antioxidant activity [170].

In CKD proteinuria ( $>500 \mathrm{mg} /$ day) seems to be causally connected to CKD progression. Alterations in kidney podocyte function or loss of podocytes can contribute to proteinuria. Effects of vitamin D on podocyte function were extensively studied in cellular and animal models [171-173]. In a rat model of diabetic nephropathy Song et al. found an amelioration of podocyte injury by calcitriol [174]. Garsen et al. showed reduced proteinuria by 1,25 -dihydroxyvitamin $\mathrm{D}$ treatment connected to reduced heparanase expression in podocytes [175]. In two animal models of kidney injury 1,25dihydroxyvitamin $\mathrm{D}$ reduced podocyte urokinase receptor expression and proteinuria [176]. In a mouse model of $\mathrm{HIV}$-associated nephropathy a downregulation of vitamin D receptor in renal tissue was observed, and HIV also in vitro downregulated vitamin $\mathrm{D}$ receptor expression in podocytes. In parallel, reactive oxygen species generation and DNA damage were upregulated, effects that could be reduced by vitamin D receptor agonist treatment [177].

Considering the abovementioned mechanisms, it is interesting now to have a look at vitamin D interventions in CKD. Several groups investigated vitamin D effects on markers of oxidative stress or enzymes with pro- or antioxidant activity. Most studies investigating vitamin D receptor agonist effects were performed with paricalcitol. Husain et al. reported that in uremic rats paricalcitol treatment reduced uremiainduced cardiac NADPH oxidase upregulation, increased uremia-impaired cardiac glutathione content, and improved the uremia-dependent reduction of cardiac copper/zinc superoxide dismutase activity [178]. Also in a uremic rat model, paricalcitol improved the uremia-dependent downregulation of renal copper/zinc superoxide dismutase protein and reduced uremia-induced oxidative stress in the kidney [179]. Another vitamin D receptor agonist, doxercalciferol, decreased inflammation and oxidative stress in a dietary fat-induced renal disease mouse model [180]. In humans direct investigation of vitamin $\mathrm{D}$ effects on tissue-specific oxidative stress is less feasible. Therefore in clinical studies mainly global parameters of oxidative stress or damage were investigated. One uncontrolled study with paricalcitol in hemodialysis patients reported a significant reduction of global parameters of oxidative stress and an increase of parameters of antioxidant capacity [181]. A recent randomized controlled trial of effects of paricalcitol in CKD stages 3 and 4 over 3 months did not show a significant influence on global markers of inflammation or oxidative stress [182].

Vitamin D effects on oxidative stress in CKD are thought to be related to effects on uremia-dependent changes of inflammatory state, antiproliferation, and immune function and hence to nonclassical vitamin D actions. It was therefore considered as reasonable to improve 25-dihydroxyvitamin D supply for extrarenal production of 1,25-dihydroxyvitamin $\mathrm{D}$ [183]. The results obtained from clinical studies testing this approach were conflicting. Markers of oxidative stress were not assessed directly but markers of immune cell activation and inflammation might be regarded as indicators. In an 8-week and a 12-week randomized controlled trial with cholecalciferol in hemodialysis patients no significant effects on inflammatory markers and cytokines could be detected [184, 185]. In three uncontrolled trials in hemodialysis patients, cholecalciferol therapy between 8 weeks and 1 year caused significant reductions of inflammatory markers and cytokines [186-188]. In CKD patients not on hemodialysis treatment a randomized controlled trial over one year did not show a sustained effect on cytokines and markers of inflammation [189]. An uncontrolled trial with 28 weeks of cholecalciferol treatment showed a significant reduction of urinary transforming-growth-factor-beta 1 [190]. The varying results of cholecalciferol interventions in CKD might be due to differences in methodology. Also, yet unrecognized differences in patient characteristics could be involved.

The overall discrepancy between vitamin $\mathrm{D}$ effects on oxidative stress markers and inflammation between preclinical and clinical studies which applies to some extent to both cholecalciferol and vitamin $\mathrm{D}$ receptor agonists is probably based on the multitude of disturbances of vitamin $\mathrm{D}$ metabolism and signal transduction in CKD. Uremiadependent impairment of 1,25-dihydroxyvitamin D production also in extrarenal cells, uremia-dependent impairment of 25-hydroxyvitamin D uptake and intracellular transport in those cells, the reduced expression of vitamin $\mathrm{D}$ receptor protein in CKD, and the disturbed interaction of vitamin $\mathrm{D}$ receptors with DNA in uremia can contribute to the lesser than expected effects of vitamin D therapy in CKD (for review of mechanisms see $[191,192])$.

More research is needed in the future, to determine in individual CKD patients those factors that result in a positive response to vitamin $\mathrm{D}$ treatment with respect to oxidative stress or inflammation. Also, new treatment strategies, which specifically target disturbances of vitamin $\mathrm{D}$ metabolism in CKD, for example, the reduction of vitamin $\mathrm{D}$ receptor protein, might be promising.

\section{Emerging Therapies for Diabetic Nephropathy}

Diabetes mellitus (DM) is a metabolic disorder characterized by chronic hyperglycemia. The chronic exposure to high glucose concentrations damages certain tissues and organs like the kidneys, for example, by noninsulin dependent glucose uptake. Interactions of hemodynamic, metabolic, and humoral factors are all thought to be involved in the pathogenesis of diabetic nephropathy (DN) $[193,194]$. Hyperglycemia activates prooxidant, profibrotic, and proinflammatory pathways leading to endothelial dysfunction, mesangial matrix accumulation, podocyte detachment and 

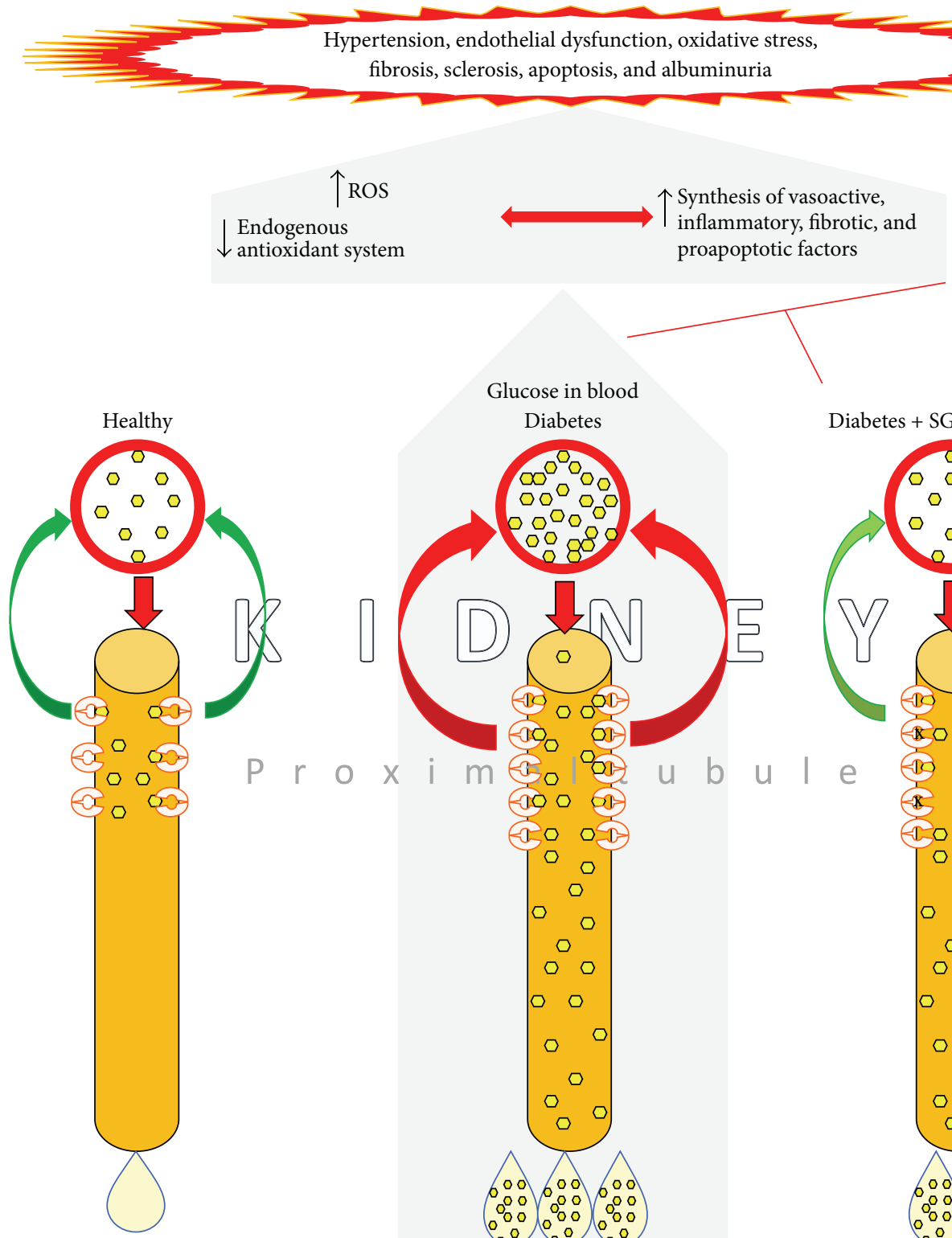
Diabetes
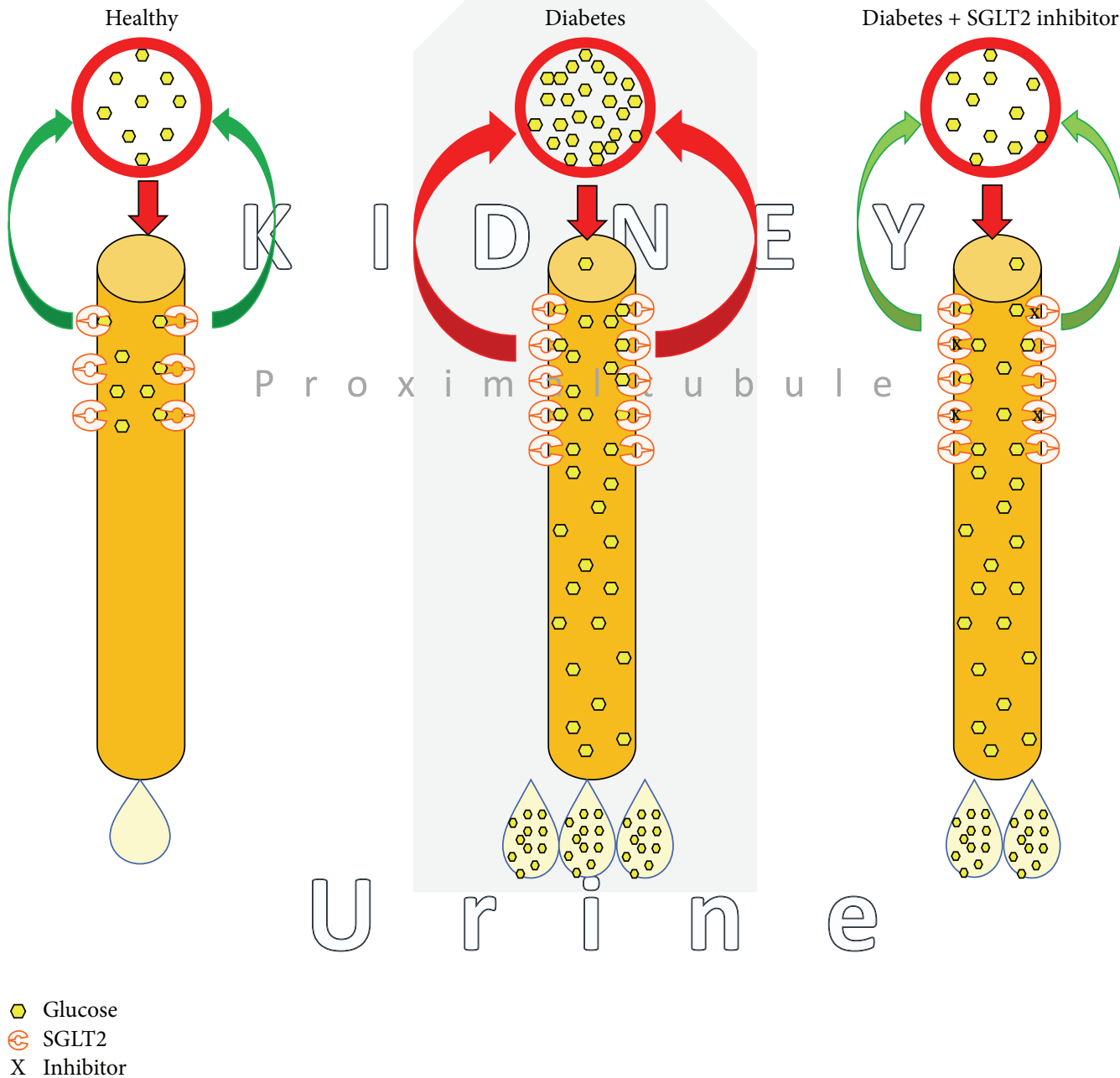

FIGURE 2: Role of sodium-glucose cotransporter 2 in blood glucose control in basal and hyperglycemic conditions and effects on blood glucose.

loss, glomerular basement membrane thickening, vacuolization in tubular epithelial cell, tubular atrophy, fibrosis, and tubulointerstitial inflammation (see Figure 2) [195-197].

The available antidiabetic agents have been developed to target one or more of the underlying defects or processes involved in DN. However, currently, therapies have not been fully effective, which makes it necessary to search for new therapeutic options for the management of this disease. Of these options, antioxidant-based therapies and inhibitors of sodium-glucose cotransporter 2 (SGLT2 inhibitors) are recent developments.

In basal condition, ninety percent of glucose filtered by the glomerulus is reabsorbed by the low-affinity/high capacity cotransporter SGLT2, which is expressed mainly on S1 and 
TABLE 2: Long term effects of SGLT2 inhibitors as approved glucose-lowering agents.

\begin{tabular}{lccc}
\hline Inhibitor & Diabetes & Effects & References \\
\hline Canagliflozin & Type 2 & Reduces GFR, $\mathrm{HbA}_{1 \mathrm{C}}, \mathrm{BW}, \mathrm{BP}, \mathrm{FPG}$. & [266, 267] \\
Dapagliflozin & Type 2 & Reduces GFR, BP, BW, $\mathrm{HbA}_{1 \mathrm{C}}$, albumin and stabilizes insulin dosing. & [268-272] \\
Empagliflozin & Type 1 & Reduces GFR, plasma $\mathrm{NO}, \mathrm{HbA}_{1 \mathrm{C}}$, arterial stiffness, heart failure hospitalization, & cardiovascular death. \\
[pragliflozin & Type 2 & Reduces $\mathrm{HbA}_{1 \mathrm{C}}, \mathrm{BW}, \mathrm{FPG}$ and improves liver function and lipid profile. & [276-278] \\
\hline
\end{tabular}

Glycated haemoglobin, $\mathrm{HbA}_{1 \mathrm{C}}$, glomerular filtration rate, GFR, fasting plasma glucose, FPG, body weight, BW, blood pressure, BP, and nitric oxide, NO.

S2 segment of renal proximal tubules (Figure 2). However, during hyperglycemia the blood glucose concentrations are high, which is associated with an increased ability to reabsorb filtered glucose [198-201], due to an increase in SGLT2 expression [201-206]. This mechanism is counterproductive for the patient since glucose in plasma increases. Chronic exposure of renal cells to high glucose concentrations therefore causes a chronic vicious circle and is harmful (Figure 2).

SGLT2 inhibitors are a new class of drugs with a unique action mechanism that is insulin-independent and depends on plasma glucose and renal function. The use of SGLT2 inhibitors (dapagliflozin, canagliflozin, empagliflozin, and ipragliflozin) significantly reduces hyperglycemia, body weight, glycated hemoglobin $\left(\mathrm{HbA}_{1 \mathrm{C}}\right)$, blood pressure (BP), hyperinsulinemia, inflammatory markers (interleukin-6 (IL6), tumor necrosis factor $\alpha$ (TNF- $\alpha$ ), monocyte chemotactic protein-1 (MCP-1), and C-reactive protein (CRP)), hyperfiltration, natriuresis, oxidative stress (OS), and glycosuria [202, 203, 207-210]. The therapeutic advantages of using SGLT2 inhibitors in clinical practice are summarized in Table 2.

Additional therapeutic benefits induced by SGLT2 inhibitors could be mediated by an indirect effect on blood glucose, which may be the most important mechanism associated with improvement of renal function and other complications related to DN (Table 2). These data suggest that SGLT2 inhibitors may have a renoprotective effect in diabetes. However, certain adverse events or potential risk related to increased glycosuria including a higher frequency of urinary infections, genital fungal infections, volume depletion, and a low risk of hypoglycemia have been described.

Recently, traditional, complementary, and alternative medicines are considered to cope with the mechanisms involved in the progression of $\mathrm{DN}$, mainly against $\mathrm{OS}$ and hyperglycemia. The use of herbal medicinal plants especially those used in folk medicine for the treatment of DM is common in the world. Among these are foods commonly consumed or their derivatives such as garlic, curcumin, moringa, cinnamon, resveratrol, and sulforaphane.

Garlic (Allium sativum) is a common cooking spice used as a folk remedy, which has been experimentally described to have antidiabetic potential. The garlic extract showed a significant improvement in blood glucose, fasting plasma glucose (FPG), $\mathrm{HbA}_{1 \mathrm{C}}$, serum insulin levels, lipid peroxidation, total antioxidant level (TAL), catalase activity (CAT), urine, and serum biochemical parameters such as albumin, urea nitrogen, and creatinine compared to that of diabetic rats. Further, garlic supplemented diabetic rats showed less glomerular glycation, loss of microvilli of proximal tubules, extravasation of red blood cells, thickness of the glomerular basement membrane, and expression of VEGF and ERK-1 compared to diabetic rats, attenuating mesangial expansion and glomerulosclerosis [211-215]. The use of garlic derivatives including S-allyl cysteine and allicin has been found effective in lowering blood glucose levels, improving OS markers (CAT, superoxide dismutase (SOD), and glutathione) and protecting cell protein and cell membranes [216, 217]. Other studies reported that garlic downregulates expression of angiotensin II AT1 receptors (AT1) and receptor for advanced glycation end products (RAGE) in renal cortical glomeruli and tubules [214, 218].

Although experimental studies described antidiabetic effects of garlic, human studies are inconclusive but showed a compelling antioxidant effect. Aged garlic extract intake (3g/day) did not affect blood glucose, $\mathrm{HbA}_{1 \mathrm{C}}$, or the lipid profile but did reduce levels of serum advanced glycation end products (AGEs) and lipid hydroperoxide in patients [219]. In contrast, other studies describe that garlic extract improves blood lipid profile, strengthens TAL, and decreased lipid peroxidation, BP, RAGE, and secretion of IL-1 and TNF in patients [220, 221].

Curcumin is a yellow pigment from Curcuma longa, commonly consumed as a flavor and coloring food. In experimental diabetes curcumin has been shown to improve blood glucose, $\mathrm{HbA}_{1 \mathrm{C}}$, lipid profile, serum creatinine, blood urea nitrogen (BUN), and kidney/body weight ratio and to significantly reduce blood concentrations of IL-6, MCP-1, TNF- $\alpha$, and OS, which was evidenced by its effects on 8-hydroxy-2' -deoxyguanosine (8-OHdG), malondialdehyde (MDA), 3-nitrotyrosine (3-NT), GSH, and antioxidant enzymes levels (SOD, CAT, and heme oxygenase-1 (HO1)) [222-227]. Curcumin decreased ROS production and apoptosis via dephosphorylation of caveolin-1 (cav-1) in kidneys and in podocytes in vitro [226].

Clinical studies report that curcumin can effectively prevent the prediabetes population from developing T2DM, attenuate proteinuria, and exert immunomodulatory effects on circulating concentrations of IL- $1 \beta$, IL- 4, IL- 8 , TGF, and VEGF [228-230]. In a recent study curcumin did not improve proteinuria, GFR, or lipid profile. However, curcumin attenuated lipid peroxidation and enhanced the antioxidant capacity in plasma [231]. On the other hand, the combination of garlic extract and curcumin decreased $\mathrm{HbA}_{1 \mathrm{C}}, \mathrm{FPG}$, and 2hour postprandial blood glucose but the treatment did not affect liver and kidney function [232]. 
It has been suggested that the beneficial effects induced by curcumin involve the downregulation of $\mathrm{Wnt} / \beta$-catenin signaling as well as PKC- $\alpha$ and PKC- $\beta 1$ activities, phosphorylated ERK1/2 in renal glomeruli, and enhanced nuclear translocation of Nrf2 and preservation of the activity of antioxidant enzymes [90, 233, 234]. Curcumin acts through normalizing the expression levels of various factors important during DN progression. This includes normalization of the levels of NOX4, p67phox, TGF- $\beta$, CTGF, osteopontin, vimentin, desmin, SREBP-1, iNOS, synaptopodin, connexin 43, erythropoietin, p300, and extracellular matrix proteins [227, 233, 234].

Moringa (Moringa oleifera L.) is the cultivated species of the genus Moringa of the family Moringaceae. The moringa extract demonstrated a beneficial effect on body weight, blood glucose concentration, renal function, lipid peroxidation, and activities of SOD, CAT, GST, and GSH in renal tissue, as well as TNF and IL1 concentrations in serum [235239]. In addition, immunoglobulins ( $\operatorname{IgA}, \operatorname{IgG}), \mathrm{FPG}$, and $\mathrm{HbA}_{1 \mathrm{C}}$ were also decreased, and the histology of both kidney and pancreas were restored with moringa treatment [235].

Clinical studies showed that moringa significantly decreased FPG, hyperglycemia, total cholesterol, triglycerides, low-density lipoprotein- (LDL-) cholesterol, and VLDL-cholesterol [240-242]. Moreover, the data revealed significant increases in serum GPx and SOD, with decreases in MDA [243].

One of the most widely used spices in the food and beverage industry is cinnamon. The administration of cinnamon to diabetic rats decreased blood glucose and lipid peroxidation and improved lipid profile and GPx, SOD, and CAT activities in the kidney [244]. Cinnamon also protects the kidney by reducing glomerular expansion, eradicating hyaline casts, decreasing the tubular dilatations, and restoring nucleus and cytoplasm material of both glomerulus and Bowman's capsule $[245,246]$. Procyanidin-B2, the active compound of cinnamon, inhibits in vitro and in vivo AGE formation and accumulation in diabetic kidney. Interestingly, procyanidinB2 prevented the loss of expression of nephrin and podocin [247].

Cinnamon seems to have a moderate effect in reducing $\mathrm{FPG}, \mathrm{HbA}_{1 \mathrm{C}}$, blood triglyceride levels, and OS markers in patients [248-250]. It has been described that the antidiabetic effect of cinnamon may be due to enhanced insulin receptor phosphorylation and the translocation of glucose transporter-4 (GLUT4) [251]. Another mechanism that explains the effects of cinnamon is an increase in the expression of peroxisome proliferator-activated receptor (PPAR), alpha and gamma receptors, thereby increasing insulin sensitivity [252].

Resveratrol (trans-3, $4^{\prime}, 5$-trihydroxystilbene), a polyphenolic compound naturally existing in grapes, has shown antioxidant activity. Resveratrol treatment ameliorates hyperglycemia, renal production of ROS, apoptosis, inflammation, and renal dysfunction in diabetes [253-258]. Moreover, resveratrol prevented the reduction in podocyte number and the disruption of both podocyte foot processes and basal infoldings [257]. In diabetic patients resveratrol significantly decreased $\mathrm{BP}, \mathrm{FBG}, \mathrm{HbA}_{1 \mathrm{C}}$, total cholesterol, and insulin resistance, while HDL was significantly increased compared to their baseline levels $[259,260]$.

The protective effects of resveratrol, with respect to cell apoptosis and ROS include activation of AMP-activated protein kinase $(\mathrm{AMPK})$, silent information regulator $\mathrm{T} 1$ (SIRT1), and PPAR $\gamma$ coactivator $1 \alpha$ (PGC- $1 \alpha)$ and the consequent effects on its target molecules PPAR $\alpha$-oestrogenrelated receptor and the phosphatidylinositol-3 kinaseprotein kinase $\mathrm{B}-\mathrm{O}$ forkhead box 3a pathway in diabetes [256]. Also, antioxidant effects of resveratrol in diabetes are related to the Nrf2/Keap1 pathway and downstream regulatory proteins [257].

Recently, it was reported that resveratrol decreased mesangial cell proliferation, glomerular basement membrane thickness, fibrosis and the expression of plasminogen activator inhibitor (PAI-1), ICAM-1, protein kinase B (Akt), vascular endothelial growth factor (VEGF), and its type 2 receptor Flk-1 and inhibited the nuclear factor-kappa B (NF$\kappa \mathrm{B})$ [258-261]. This suggests that resveratrol may attenuate $\mathrm{DN}$ via the modulation of $\mathrm{Akt} / \mathrm{NF}-\kappa \mathrm{B}$ pathway and influences on angiogenesis.

Sulforaphane is an organosulfur compound obtained from crucifers vegetables such as broccoli, brussels sprouts, or cabbages. Sulforaphane exhibits antioxidant and antidiabetic properties in diabetes. Sulforaphane prevents diabetesinduced inflammation, renal dysfunction, and oxidative and nitrosative damage [262, 263]. In patients, sulforaphane decreased MDA, oxidized LDL-cholesterol, and oxidative stress index and there was a significant increase in TAL [264].

Some studies have shown that activation of Nrf2 by sulforaphane improved hyperglycemia, albuminuria, pathological alterations in the glomerulus, and oxidative damage and suppressed the expression of TGF- $\beta 1, F N, C o l$ IV, and p 21 both in vivo and in human renal mesangial cells [265]. Also, sulforaphane increased Nrf2 at protein and mRNA levels in kidney, which leads to a higher expression of $\mathrm{NAD}(\mathrm{P}) \mathrm{H}$ : Quinone Oxidoreductase 1 (NQO1), HO-1, SOD1, SOD2, and CAT at mRNA and protein levels [262, 263].

All these studies suggest that those emerging therapies could be a therapeutic option in the combat of DN (see Figure 3). Although in experimental models the results have been promising, in a clinical setting they are still controversial. The discrepancy might be accounted for by differences in physiology between laboratory animals and humans but also by differences in the type of preparation and used concentrations; thus, the chemical composition of these preparations varies widely and the biological responses are different. Another possible reason for differences between clinical studies and experimental ones may be deficiencies in methodology and different treatment durations. Experimentally, the dose and the duration of medication can be exactly controlled; however in humans, sufficient control of these aspects can be challenging.

In conclusion, hyperglycemia and oxidative stress plays a key role in the progression of diabetic nephropathy (Figure 3). Emerging therapies achieve their beneficial effects through glycemic control and regulation of antioxidant status, suggesting them as attractive therapeutic alternatives (Figure 3). However, results from clinical trials have been 


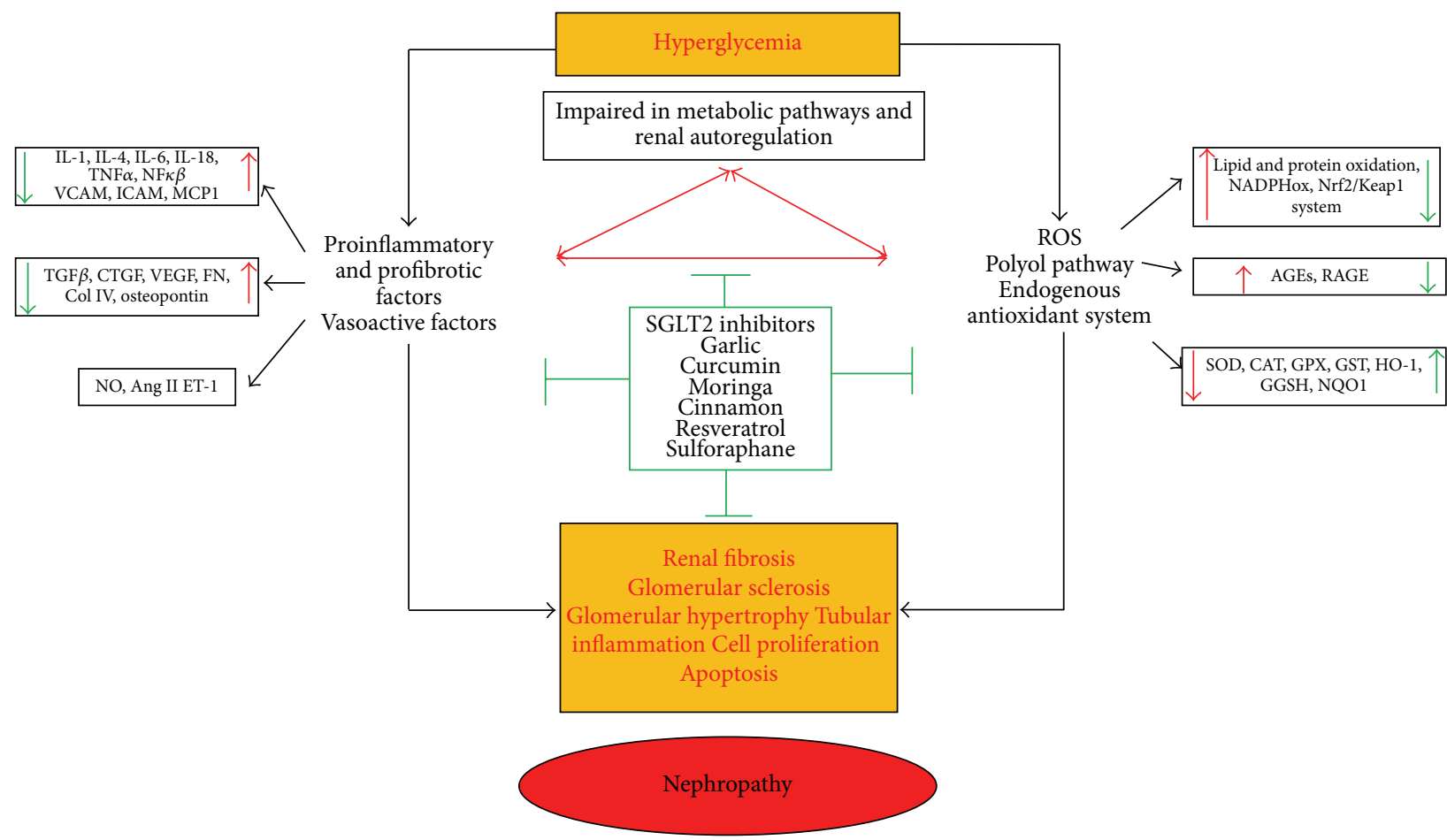

FIgURE 3: The pathophysiological mechanism of diabetic nephropathy and targets for emerging therapies. Advanced glycation end products (AGEs), endothelin-1 (ET-1), receptor for AGEs (RAGES), superoxide dismutase (SOD), catalase (CAT), nicotinamide adenine dinucleotide phosphate oxidase (NADPHox), glutathione (GSH), glutathione peroxidase (GPX), glutathione reductase (GR) and glutathiones-transferase (GST), transforming growth factor- $\beta 1$ (TGF- $\beta 1$ ), tumor necrosis factor- $\alpha$ (TNF- $\alpha$ ), reactive oxygen species (ROS), sodiumglucose cotransporter 2 (SGLT2), nuclear transcription factor-kappa-B (NF- $\kappa$ B), vascular endothelial growth factor (VEGF), Monocyte Chemoattractant Protein (MCP-1), connective tissue growth factor (CTGF), fibronectin (FN), vascular cell adhesion molecule-1 (VCAM1), intracellular adhesion molecule-1 (ICAM-1), heme oxygenase-1 (HO-1), NF-E2-related factor-2 (Nrf2), and collagen type IV (col IV).

inconclusive so far. Therefore, further studies are needed to ascertain whether the new alternative options offer benefits as first-line drugs or adjuvant medication in clinical practice.

\section{Conclusions}

Taken together, the knowledge about pathogenic aspects of oxidative stress for the progression and for complications in chronic kidney disease has significantly been extended. New therapeutic antioxidant approaches are available but are not yet satisfyingly developed and validated.

\section{Competing Interests}

The authors have no competing interests to declare.

\section{Acknowledgments}

José Pedraza-Chaverri, Laura G. Sánchez-Lozada, Horacio Osorio-Alonso, and Edilia Tapia were supported by the Research Grants 252008, 133232, 155604, and 167949 from National Council of Science and Technology (CONACYT), Mexico. They thank Fernando García-Arroyo, Magdalena Cristóbal, and Virgilia Soto who supported the studies about hyperuricemia at Laboratory of Renal Physiopathology, INC Ignacio Chávez, Mexico City, Mexico.

\section{References}

[1] D. M. Small, J. S. Coombes, N. Bennett, D. W. Johnson, and G. C. Gobe, "Oxidative stress, anti-oxidant therapies and chronic kidney disease," Nephrology, vol. 17, no. 4, pp. 311-321, 2012.

[2] P. S. Tucker, A. T. Scanlan, and V. J. Dalbo, "Chronic kidney disease influences multiple systems: describing the relationship between oxidative stress, inflammation, kidney damage, and concomitant disease," Oxidative Medicine and Cellular Longevity, vol. 2015, Article ID 806358, 8 pages, 2015.

[3] Kidney Disease: Improving Global Outcomes (KDIGO) CKD Work Group, "KDIGO 2012 clinical practice guideline for the evaluation and management of chronic kidney disease," Kidney International Supplements, vol. 3, no. 1, pp. 1-150, 2013.

[4] K. T. Mills, Y. Xu, W. Zhang et al., "A systematic analysis of worldwide population-based data on the global burden of chronic kidney disease in 2010," Kidney International, vol. 88, no. 5, pp. 950-957, 2015.

[5] C. Martín-Cleary and A. Ortiz, "CKD hotspots around the world: where, why and what the lessons are. A CKJ review series," Clinical Kidney Journal, vol. 7, no. 6, Article ID sful18, pp. 519-523, 2014. 
[6] G. Abraham, S. Varughese, T. Thandavan et al., "Chronic kidney disease hotspots in developing countries in South Asia," Clinical Kidney Journal, vol. 9, no. 1, pp. 135-141, 2016.

[7] J. R. Ingelfinger, K. Kalantar-Zadeh, and F. Schaefer, "Averting the legacy of kidney disease-focus on childhood," Brazilian Journal of Medical and Biological Research, vol. 49, no. 5, Article ID e5314, 2016.

[8] M. Baumgarten and T. Gehr, "Chronic kidney disease: detection and evaluation," American Family Physician, vol. 84, no. 10, pp. 1138-1148, 2011.

[9] P. F. Mount and D. A. Power, "Balancing the energy equation for healthy kidneys," Journal of Pathology, vol. 237, no. 4, pp. 407410, 2016.

[10] K. S. Hodgkins and H. W. Schnaper, "Tubulointerstitial injury and the progression of chronic kidney disease," Pediatric Nephrology, vol. 27, no. 6, pp. 901-909, 2012.

[11] M. Sud and D. M. J. Naimark, "Cardiovascular disease in chronic kidney disease in 2015," Current Opinion in Nephrology \& Hypertension, vol. 25, no. 3, pp. 203-207, 2016.

[12] R. T. Gansevoort, R. Correa-Rotter, B. R. Hemmelgarn et al., "Chronic kidney disease and cardiovascular risk: epidemiology, mechanisms, and prevention," The Lancet, vol. 382, no. 9889, pp. 339-352, 2013.

[13] G. Ruiz-Hurtado, P. Sarafidis, M. S. Fernández-Alfonso, B. Waeber, and L. M. Ruilope, "Global cardiovascular protection in chronic kidney disease," Nature Reviews Cardiology, 2016.

[14] M. Liu, X. C. Li, L. Lu et al., "Cardiovascular disease and its relationship with chronic kidney disease," European Review for Medical and Pharmacological Sciences, vol. 18, no. 19, pp. 29182926, 2014.

[15] T. Isakova, J. H. Ix, S. M. Sprague et al., "Rationale and approaches to phosphate and fibroblast growth factor 23 reduction in CKD," Journal of the American Society of Nephrology, vol. 26, no. 10, pp. 2328-2339, 2015.

[16] S. Lekawanvijit, A. R. Kompa, and H. Krum, "Protein-bound uremic toxins: a long overlooked culprit in cardiorenal syndrome," American Journal of Physiology-Renal Physiology, 2016.

[17] N. D. Vaziri, Y. Y. Zhao, and M. V. Pahl, "Altered intestinal microbial flora and impaired epithelial barrier structure and function in CKD: the nature, mechanisms, consequences and potential treatment," Nephrology, Dialysis, Transplantation, vol. 31, no. 5, pp. 737-746, 2016.

[18] A. E. M. Stinghen, Z. A. Massy, H. Vlassara, G. E. Striker, and A. Boullier, "Uremic toxicity of advanced glycation end products in CKD," Journal of the American Society of Nephrology, vol. 27, no. 2, pp. 354-370, 2016.

[19] B. Giam, D. M. Kaye, and N. W. Rajapakse, "Role of renal oxidative stress in the pathogenesis of the cardiorenal syndrome," Heart, Lung and Circulation, 2016.

[20] S. Zewinger, T. Schumann, D. Fliser, and T. Speer, "Innate immunity in CKD-associated vascular diseases," Nephrology Dialysis Transplantation, 2015.

[21] E. Gonzalez-Parra, J. Rojas-Rivera, J. Tunón, M. Praga, A. Ortiz, and J. Egido, "Vitamin D receptor activation and cardiovascular disease," Nephrology Dialysis Transplantation, vol. 27, no. 4, pp. iv17-iv21, 2012.

[22] J. P. Kooman, P. Kotanko, A. M. W. J. Schols, P. G. Shiels, and P. Stenvinkel, "Chronic kidney disease and premature ageing," Nature Reviews Nephrology, vol. 10, no. 12, pp. 732-742, 2014.
[23] A. Machowska, J. J. Carrero, B. Lindholm, and P. Stenvinkel, "Therapeutics targeting persistent inflammation in chronic kidney disease," Translational Research, vol. 167, no. 1, pp. 204213, 2016.

[24] R. Kramann, J. Floege, M. Ketteler, N. Marx, and V. M. Brandenburg, "Medical options to fight mortality in end-stage renal disease: a review of the literature," Nephrology Dialysis Transplantation, vol. 27, no. 12, pp. 4298-4307, 2012.

[25] M. Jun, V. Venkataraman, M. Razavian et al., "Antioxidants for chronic kidney disease," Cochrane Database of Systematic Reviews, no. 10, Article ID CD008176, 2012.

[26] S. Van Laecke, W. Van Biesen, and R. Vanholder, "The paradox of bardoxolone methyl: a call for every witness on the stand?" Diabetes, Obesity and Metabolism, vol. 17, no. 1, pp. 9-14, 2015.

[27] C. C. Sung, Y. C. Hsu, C. C. Chen, Y. F. Lin, and C. C. $\mathrm{Wu}$, "Oxidative stress and nucleic acid oxidation in patients with chronic kidney disease," Oxidative Medicine and Cellular Longevity, vol. 2013, Article ID 301982, 15 pages, 2013.

[28] D. M. Small and G. C. Gobe, "Oxidative stress and antioxidant therapy in chronic kidney and cardiovascular disease," in Oxidative Stress and Chronic Degenerative Diseases-A Role for Antioxidants, J. A. Morales-González, Ed., chapter 10, InTech, Rijeka, Croatia, 2013.

[29] S. K. Yang, L. Xiao, B. Xu, X. X. Xu, F. Y. Liu, and L. Sun, "Effects of vitamin E-coated dialyzer on oxidative stress and inflammation status in hemodialysis patients: a systematic review and meta-analysis," Renal Failure, vol. 36, no. 5, pp. 722731, 2014.

[30] T. I. Kassimatis and D. J. A. Goldsmith, "Statins in chronic kidney disease and kidney transplantation," Pharmacological Research, vol. 88, pp. 62-73, 2014.

[31] G. Lastra, S. Dhuper, M. S. Johnson, and J. R. Sowers, "Salt, aldosterone, and insulin resistance: impact on the cardiovascular system," Nature Reviews Cardiology, vol. 7, no. 10, pp. 577$584,2010$.

[32] L. Vitetta, A. W. Linnane, and G. C. Gobe, "From the gastrointestinal tract (GIT) to the Kidneys: Live bacterial cultures (probiotics) mediating reductions of uremic toxin levels via free radical signaling," Toxins, vol. 5, no. 11, pp. 2042-2057, 2013.

[33] A. Ramezani and D. S. Raj, "The gut microbiome, kidney disease, and targeted interventions," Journal of the American Society of Nephrology, vol. 25, no. 4, pp. 657-670, 2014.

[34] A. H. Van Craenenbroeck, E. M. Van Craenenbroeck, E. Kouidi, C. J. Vrints, M. M. Couttenye, and V. M. Conraads, "Vascular effects of exercise training in CKD: current evidence and pathophysiological mechanisms," Clinical Journal of the American Society of Nephrology, vol. 9, no. 7, pp. 1305-1318, 2014.

[35] Z. A. Massy, P. Stenvinkel, and T. B. Drueke, "The role of oxidative stress in chronic kidney disease," Seminars in Dialysis, vol. 22, no. 4, pp. 405-408, 2009.

[36] M. Bossola and L. Tazza, "Wishful thinking: the surprisingly sparse evidence for a relationship between oxidative stress and cardiovascular disease in hemodialysis patients," Seminars in Dialysis, vol. 28, no. 3, pp. 224-230, 2015.

[37] H. H. Schmidt, R. Stocker, C. Vollbracht et al., "Antioxidants in translational medicine," Antioxidants and Redox Signaling, vol. 23, no. 14, pp. 1130-1143, 2015.

[38] B. B. Ratliff, W. Abdulmahdi, R. Pawar, and M. S. Wolin, "Oxidant mechanisms in renal injury and disease," Antioxidants \& Redox Signaling, 2016. 
[39] Z. Mitrogianni, A. Barbouti, D. Galaris, and K. C. Siamopoulos, "Oxidative modification of albumin in predialysis, hemodialysis, and peritoneal dialysis patients," Nephron Clinical Practice, vol. 113, no. 3, pp. c234-c240, 2009.

[40] I. Karamouzis, P. A. Sarafidis, M. Karamouzis et al., "Increase in oxidative stress but not in antioxidant capacity with advancing stages of chronic kidney disease," American Journal of Nephrology, vol. 28, no. 3, pp. 397-404, 2008.

[41] E. Dounousi, E. Papavasiliou, A. Makedou et al., "Oxidative stress is progressively enhanced with advancing stages of CKD," American Journal of Kidney Diseases, vol. 48, no. 5, pp. 752-760, 2006.

[42] C. Fleury, B. Mignotte, and J.-L. Vayssière, "Mitochondrial reactive oxygen species in cell death signaling," Biochimie, vol. 84, no. 2-3, pp. 131-141, 2002.

[43] F. Addabbo, M. Montagnani, and M. S. Goligorsky, "Mitochondria and reactive oxygen species," Hypertension, vol. 53, no. 6, pp. 885-892, 2009.

[44] M. Zhan, C. Brooks, F. Liu, L. Sun, and Z. Dong, "Mitochondrial dynamics: regulatory mechanisms and emerging role in renal pathophysiology," Kidney International, vol. 83, no. 4, pp. 568$581,2013$.

[45] S. I. Harris, R. S. Balaban, L. Barrett, and L. J. Mandel, "Mitochondrial respiratory capacity and $\mathrm{Na}^{+}$- and $\mathrm{K}^{+}$-dependent adenosine triphosphatase-mediated ion transport in the intact renal cell," Journal of Biological Chemistry, vol. 256, no. 20, pp. 10319-10328, 1981.

[46] R. S. Balaban and L. J. Mandel, "Metabolic substrate utilization by rabbit proximal tubule. An NADH fluorescence study," American Journal of Physiology-Renal Fluid and Electrolyte Physiology, vol. 254, no. 3, pp. F407-F416, 1988.

[47] L. J. Mandel, "Primary active sodium transport, oxygen consumption, and ATP: coupling and regulation," Kidney International, vol. 29, no. 1, pp. 3-9, 1986.

[48] P. Deetjen and K. Kramer, "The relation of $\mathrm{O}_{2}$ consumption by the kidney to Na re-resorption," Pflüger's Archiv für die gesamte Physiologie des Menschen und der Tiere, vol. 273, no. 6, pp. 636650, 1961.

[49] S. Kume, T. Uzu, K. Horiike et al., "Calorie restriction enhances cell adaptation to hypoxia through Sirtl-dependent mitochondrial autophagy in mouse aged kidney," Journal of Clinical Investigation, vol. 120, no. 4, pp. 1043-1055, 2010.

[50] P. Sansanwal, B. Yen, W. A. Gahl et al., "Mitochondrial autophagy promotes cellular injury in nephropathic cystinosis," Journal of the American Society of Nephrology, vol. 21, no. 2, pp. 272-283, 2010.

[51] J. M. Weinberg, "Mitochondrial biogenesis in kidney disease," Journal of the American Society of Nephrology, vol. 22, no. 3, pp. 431-436, 2011.

[52] C. A. Virbasius, J. V. Virbasius, and R. C. Scarpulla, "NRF1 , an activator involved in nuclear-mitochondrial interactions, utilizes a new DNA-binding domain conserved in a family of developmental regulators," Genes and Development, vol. 7, no. 12, pp. 2431-2445, 1993.

[53] Z. Wu, P. Puigserver, U. Andersson et al., "Mechanisms controlling mitochondrial biogenesis and respiration through the thermogenic coactivator PGC-1," Cell, vol. 98, no. 1, pp. 115-124, 1999.

[54] H. Liang and W. F. Ward, "PGC-1 $\alpha$ : a key regulator of energy metabolism," American Journal of Physiology-Advances in Physiology Education, vol. 30, no. 4, pp. 145-151, 2006.
[55] K. A. Rasbach and R. G. Schnellmann, "PGC-1 $\alpha$ overexpression promotes recovery from mitochondrial dysfunction and cell injury," Biochemical and Biophysical Research Communications, vol. 355, no. 3, pp. 734-739, 2007.

[56] Z. Yang and D. J. Klionsky, "Mammalian autophagy: core molecular machinery and signaling regulation," Current Opinion in Cell Biology, vol. 22, no. 2, pp. 124-131, 2010.

[57] N. Mizushima and M. Komatsu, "Autophagy: renovation of cells and tissues," Cell, vol. 147, no. 4, pp. 728-741, 2011.

[58] Z. Wang and M. E. Choi, "Autophagy in kidney health and disease," Antioxidants and Redox Signaling, vol. 20, no. 3, pp. 519-537, 2014.

[59] M. P. Murphy, "How mitochondria produce reactive oxygen species," Biochemical Journal, vol. 417, no. 1, pp. 1-13, 2009.

[60] T. Nishikawa, D. Edelstein, X. L. Du et al., "Normalizing mitochondrial superoxide production blocks three pathways of hyperglycaemic damage," Nature, vol. 404, no. 6779, pp. 787790, 2000.

[61] B. Westermann, "Bioenergetic role of mitochondrial fusion and fission," Biochimica et Biophysica Acta (BBA): Bioenergetics, vol. 1817, no. 10, pp. 1833-1838, 2012.

[62] A. D. Mozdy, J. M. McCaffery, and J. M. Shaw, “Dnmlp GTPasemediated mitochondrial fission is a multi-step process requiring the novel integral membrane component Fislp," Journal of Cell Biology, vol. 151, no. 2, pp. 367-379, 2000.

[63] E. Smirnova, L. Griparic, D.-L. Shurland, and A. M. van der Bliek, "Dynamin-related protein Drp1 is required for mitochondrial division in mammalian cells," Molecular Biology of the Cell, vol. 12, no. 8, pp. 2245-2256, 2001.

[64] D. C. Chan, "Mitochondria: dynamic organelles in disease, aging, and development," Cell, vol. 125, no. 7, pp. 1241-1252, 2006.

[65] S. L. Archer, "Mitochondrial dynamics-mitochondrial fission and fusion in human diseases," The New England Journal of Medicine, vol. 369, no. 23, pp. 2236-2251, 2013.

[66] S. A. Detmer and D. C. Chan, "Functions and dysfunctions of mitochondrial dynamics," Nature Reviews Molecular Cell Biology, vol. 8, no. 11, pp. 870-879, 2007.

[67] C. Brooks, Q. Wei, S.-G. Cho, and Z. Dong, "Regulation of mitochondrial dynamics in acute kidney injury in cell culture and rodent models," Journal of Clinical Investigation, vol. 119, no. 5, pp. 1275-1285, 2009.

[68] J. M. Gall, Z. Wang, M. Liesa et al., "Role of mitofusin 2 in the renal stress response," PLoS ONE, vol. 7, no. 1, Article ID e31074, 2012.

[69] R. Che, Y. Yuan, S. Huang, and A. Zhang, "Mitochondrial dysfunction in the pathophysiology of renal diseases," American Journal of Physiology: Renal Physiology, vol. 306, no. 4, pp. F367F378, 2014.

[70] K. A. Nath, A. J. Croatt, and T. H. Hostetter, "Oxygen consumption and oxidant stress in surviving nephrons," American Journal of Physiology-Renal Fluid and Electrolyte Physiology, vol. 258, no. 5, pp. F1354-F1362, 1990.

[71] L. V. Fedorova, A. Tamirisa, D. J. Kennedy et al., "Mitochondrial impairment in the five-sixth nephrectomy model of chronic renal failure: proteomic approach," BMC Nephrology, vol. 14, no. 1, article 209, 2013.

[72] L. Sun, P. Xie, J. Wada et al., "Raplb GTPase ameliorates glucoseinduced mitochondrial dysfunction," Journal of the American Society of Nephrology, vol. 19, no. 12, pp. 2293-2301, 2008. 
[73] I. Daehn, G. Casalena, T. Zhang et al., "Endothelial mitochondrial oxidative stress determines podocyte depletion in segmental glomerulosclerosis," Journal of Clinical Investigation, vol. 124, no. 4, pp. 1608-1621, 2014.

[74] J.-F. Chen, H. Liu, H.-F. Ni et al., "Improved mitochondrial function underlies the protective effect of pirfenidone against tubulointerstitial fibrosis in 5/6 nephrectomized rats," PLoS ONE, vol. 8, no. 12, Article ID e83593, 2013.

[75] W. Wang, Y. Wang, J. Long et al., "Mitochondrial fission triggered by hyperglycemia is mediated by ROCK1 activation in podocytes and endothelial cells," Cell Metabolism, vol. 15, no. 2, pp. 186-200, 2012.

[76] D. Dinour, S. Mini, S. Polak-Charcon, D. Lotan, and E. J. Holtzman, "Progressive nephropathy associated with mitochondrial tRNA gene mutation," Clinical Nephrology, vol. 62, no. 2, pp. 149-154, 2004.

[77] J. Finsterer, “Mitochondriopathies," European Journal of Neurology, vol. 11, no. 3, pp. 163-186, 2004.

[78] P. Niaudet and A. Rotig, "The kidney in mitochondrial cytopathies," Kidney International, vol. 51, no. 4, pp. 1000-1007, 1997.

[79] G. B. Piccoli, L. D. Bonino, P. Campisi et al., "Chronic kidney disease, severe arterial and arteriolar sclerosis and kidney neoplasia: on the spectrum of kidney involvement in MELAS syndrome," BMC Nephrology, vol. 13, , article 9, 2012.

[80] S. Sangkhathat, T. Kusafuka, A. Yoneda et al., "Renal cell carcinoma in a pediatric patient with an inherited mitochondrial mutation," Pediatric Surgery International, vol. 21, no. 9, pp. 745$748,2005$.

[81] Y. Yuan, Y. Chen, P. Zhang et al., "Mitochondrial dysfunction accounts for aldosterone-induced epithelial-to-mesenchymal transition of renal proximal tubular epithelial cells," Free Radical Biology and Medicine, vol. 53, no. 1, pp. 30-43, 2012.

[82] Ş. Güçer, B. Talim, E. Aşan et al., "Focal segmental glomerulosclerosis associated with mitochondrial cytopathy: report of two cases with special emphasis on podocytes," Pediatric and Developmental Pathology, vol. 8, no. 6, pp. 710-717, 2005.

[83] M. Su, A.-R. Dhoopun, Y. Yuan et al., "Mitochondrial dysfunction is an early event in aldosterone-induced podocyte injury," American Journal of Physiology-Renal Physiology, vol. 305, no. 4, pp. F520-F531, 2013.

[84] C. Zhu, S. Huang, Y. Yuan et al., "Mitochondrial dysfunction mediates aldosterone-induced podocyte damage: a therapeutic target of PPAR $y$," The American Journal of Pathology, vol. 178, no. 5, pp. 2020-2031, 2011.

[85] A. Seidowsky, M. Hoffmann, F. Glowacki et al., "Renal involvement in MELAS syndrome-a series of 5 cases and review of the literature," Clinical Nephrology, vol. 80, no. 6, pp. 456-463, 2013.

[86] C. Quinzii, A. Naini, L. Salviati et al., "A mutation in parahydroxybenzoate-polyprenyl transferase (COQ2) causes primary coenzyme Q10 deficiency," American Journal of Human Genetics, vol. 78, no. 2, pp. 345-349, 2006.

[87] G. Zaza, S. Granata, V. Masola et al., "Downregulation of nuclear-encoded genes of oxidative metabolism in dialyzed chronic kidney disease patients," PLoS ONE, vol. 8, no. 10, Article ID e77847, 2013.

[88] L. L. Dugan, Y.-H. You, S. S. Ali et al., "AMPK dysregulation promotes diabetes-related reduction of superoxide and mitochondrial function," The Journal of Clinical Investigation, vol. 123, no. 11, pp. 4888-4899, 2013.
[89] S. Granata, G. Zaza, S. Simone et al., "Mitochondrial dysregulation and oxidative stress in patients with chronic kidney disease," BMC Genomics, vol. 10, article 388, 2009.

[90] E. Tapia, V. Soto, K. M. Ortiz-Vega et al., "Curcumin induces Nrf2 nuclear translocation and prevents glomerular hypertension, hyperfiltration, oxidant stress, and the decrease in antioxidant enzymes in 5/6 nephrectomized rats," Oxidative Medicine and Cellular Longevity, vol. 2012, Article ID 269039, 14 pages, 2012.

[91] S. Granata, A. Dalla Gassa, P. Tomei, A. Lupo, and G. Zaza, "Mitochondria: a new therapeutic target in chronic kidney disease," Nutrition and Metabolism, vol. 12, article 44, 2015.

[92] M. Sumida, K. Doi, E. Ogasawara et al., "Regulation of mitochondrial dynamics by dynamin-related protein-1 in acute cardiorenal syndrome," Journal of the American Society of Nephrology, vol. 26, no. 10, pp. 2378-2387, 2015.

[93] S. Hernández-Reséndiz, F. Correa, W. R. García-Niño et al., "Cardioprotection by curcumin post-treatment in rats with established chronic kidney disease," Cardiovascular Drugs and Therapy, vol. 29, no. 2, pp. 111-120, 2015.

[94] D. Taylor, S. Bhandari, and A.-M. L. Seymour, "Mitochondrial dysfunction in uremic cardiomyopathy," American Journal of Physiology-Renal Physiology, vol. 308, no. 6, pp. F579-F587, 2015.

[95] B. N. Ames, R. Cathcart, E. Schwiers, and P. Hochstein, "Uric acid provides an antioxidant defense in humans against oxidant- and radical-caused aging and cancer: a hypothesis," Proceedings of the National Academy of Sciences of the United States of America, vol. 78, no. 11, pp. 6858-6862, 1981.

[96] G. L. Squadrito, R. Cueto, A. E. Splenser et al., "Reaction of uric acid with peroxynitrite and implications for the mechanism of neuroprotection by uric acid," Archives of Biochemistry and Biophysics, vol. 376, no. 2, pp. 333-337, 2000.

[97] J. A. Sofaer and A. E. H. Emery, "Genes for super-intelligence?" Journal of Medical Genetics, vol. 18, no. 6, pp. 410-413, 1981.

[98] S. Watanabe, D.-H. Kang, L. Feng et al., "Uric acid, hominoid evolution, and the pathogenesis of salt-sensitivity," Hypertension, vol. 40, no. 3, pp. 355-360, 2002.

[99] M. Bagnati, C. Perugini, C. Cau, R. Bordone, E. Albano, and G. Bellomo, "When and why a water-soluble antioxidant becomes pro-oxidant during copper-induced low-density lipoprotein oxidation: a study using uric acid," Biochemical Journal, vol. 340, no. 1, pp. 143-152, 1999.

[100] G. Bellomo, S. Venanzi, C. Verdura, P. Saronio, A. Esposito, and M. Timio, "Association of uric acid with change in kidney function in healthy normotensive individuals," American Journal of Kidney Diseases, vol. 56, no. 2, pp. 264-272, 2010.

[101] P. C. Grayson, S. Y. Kim, M. Lavalley, and H. K. Choi, "Hyperuricemia and incident hypertension: a systematic review and meta-analysis," Arthritis Care and Research, vol. 63, no. 1, pp. 102-110, 2011.

[102] R. P. Obermayr, C. Temml, G. Gutjahr, M. Knechtelsdorfer, R. Oberbauer, and R. Klauser-Braun, "Elevated uric acid increases the risk for kidney disease," Journal of the American Society of Nephrology, vol. 19, no. 12, pp. 2407-2413, 2008.

[103] D. E. Weiner, H. Tighiouart, E. F. Elsayed, J. L. Griffith, D. N. Salem, and A. S. Levey, "Uric acid and incident kidney disease in the community," Journal of the American Society of Nephrology, vol. 19, no. 6, pp. 1204-1211, 2008.

[104] L. H. Ficociello, E. T. Rosolowsky, M. A. Niewczas et al., "Highnormal serum uric acid increases risk of early progressive renal 
function loss in type 1 diabetes: results of a 6-year follow-up," Diabetes Care, vol. 33, no. 6, pp. 1337-1343, 2010.

[105] W. J. Kim, S. S. Kim, M. J. Bae et al., "High-normal serum uric acid predicts the development of chronic kidney disease in patients with type 2 diabetes mellitus and preserved kidney function," Journal of Diabetes and its Complications, vol. 28, no. 2, pp. 130-134, 2014.

[106] E. T. Rosolowsky, L. H. Ficociello, N. J. Maselli et al., "Highnormal serum uric acid is associated with impaired glomerular filtration rate in nonproteinuric patients with type 1 diabetes," Clinical Journal of the American Society of Nephrology, vol. 3, no. 3, pp. 706-713, 2008.

[107] R. J. Johnson, S. Titte, J. R. Cade, B. A. Rideout, and W. J. Oliver, "Uric acid, evolution and primitive cultures," Seminars in Nephrology, vol. 25, no. 1, pp. 3-8, 2005.

[108] D. B. Corry, P. Eslami, K. Yamamoto, M. D. Nyby, H. Makino, and M. L. Tuck, "Uric acid stimulates vascular smooth muscle cell proliferation and oxidative stress via the vascular reninangiotensin system," Journal of Hypertension, vol. 26, no. 2, pp. 269-275, 2008.

[109] M. A. Lanaspa, L. G. Sanchez-Lozada, Y.-J. Choi et al., "Uric acid induces hepatic steatosis by generation of mitochondrial oxidative stress: the otential role in fructose-dependent and independent fatty liver," The Journal of Biological Chemistry, vol. 287, no. 48, pp. 40732-40744, 2012.

[110] M.-A. Yu, L. G. Sánchez-Lozada, R. J. Johnson, and D.-H. Kang, "Oxidative stress with an activation of the renin-angiotensin system in human vascular endothelial cells as a novel mechanism of uric acid-induced endothelial dysfunction," Journal of Hypertension, vol. 28, no. 6, pp. 1234-1242, 2010.

[111] Y. Y. Sautin, T. Nakagawa, S. Zharikov, and R. J. Johnson, "Adverse effects of the classic antioxidant uric acid in adipocytes: NADPH oxidase-mediated oxidative/nitrosative stress," American Journal of Physiology: Cell Physiology, vol. 293, no. 2, pp. C584-C596, 2007.

[112] L. G. Sánchez-Lozada, M. A. Lanaspa, M. Cristóbal-García et al., "Uric acid-induced endothelial dysfunction is associated with mitochondrial alterations and decreased intracellular ATP concentrations," Nephron Experimental Nephrology, vol. 121, no. 3-4, pp. e71-e78, 2013.

[113] D. Verzola, E. Ratto, B. Villaggio et al., "Uric acid promotes apoptosis in human proximal tubule cells by oxidative stress and the activation of NADPH oxidase NOX 4," PLOS ONE, vol. 9, no. 12, Article ID e115210, 2014.

[114] J. Xiao, C. Fu, X. Zhang et al., "Soluble monosodium urate, but not its crystal, induces toll like receptor 4-dependent immune activation in renal mesangial cells," Molecular Immunology, vol. 66, no. 2, pp. 310-318, 2015.

[115] Y. Zhuang, Q. Feng, G. Ding et al., "Activation of ERK1/2 by $\mathrm{NADPH}$ oxidase-originated reactive oxygen species mediates uric acid-induced mesangial cell proliferation," American Journal of Physiology: Renal Physiology, vol. 307, no. 4, pp. F396F406, 2014.

[116] Y. Isaka, Y. Takabatake, A. Takahashi, T. Saitoh, and T. Yoshimori, "Hyperuricemia-induced inflammasome and kidney diseases," Nephrology Dialysis Transplantation, vol. 31, no. 6, pp. 890-896, 2016.

[117] L. G. Sánchez-Lozada, V. Soto, E. Tapia et al., "Role of oxidative stress in the renal abnormalities induced by experimental hyperuricemia," American Journal of Physiology: Renal Physiology, vol. 295, no. 4, pp. F1134-F1141, 2008.
[118] Y. Y. Sautin and R. J. Johnson, "Uric acid: the oxidantantioxidant paradox," Nucleosides, Nucleotides and Nucleic Acids, vol. 27, no. 6-7, pp. 608-619, 2008.

[119] R. J. Johnson, M. S. Segal, T. Srinivas et al., "Essential hypertension, progressive renal disease, and uric acid: a pathogenetic link?" Journal of the American Society of Nephrology, vol. 16, no. 7, pp. 1909-1919, 2005.

[120] M. A. Lanaspa, E. Tapia, V. Soto, Y. Sautin, and L. G. SánchezLozada, "Uric acid and fructose: potential biological mechanisms," Seminars in Nephrology, vol. 31, no. 5, pp. 426-432, 2011.

[121] J. F. Baker, E. Krishnan, L. Chen, and H. R. Schumacher, "Serum uric acid and cardiovascular disease: recent developments, and where do they leave us?" The American Journal of Medicine, vol. 118, no. 8, pp. 816-826, 2005.

[122] K. Y. K. Wong, R. S. Macwalter, H. W. Fraser, I. Crombie, S. A. Ogston, and A. D. Struthers, "Urate predicts subsequent cardiac death in stroke survivors," European Heart Journal, vol. 23, no. 10, pp. 788-793, 2002.

[123] E. J. Newman, F. S. Rahman, K. R. Lees, C. J. Weir, and M. R. Walters, "Elevated serum urate concentration independently predicts poor outcome following stroke in patients with diabetes," Diabetes/Metabolism Research and Reviews, vol. 22, no. 1, pp. 79-82, 2006.

[124] C. J. Weir, S. W. Muir, M. R. Walters, and K. R. Lees, "Serum urate as an independent predictor of poor outcome and future vascular events after acute stroke," Stroke, vol. 34, no. 8, pp. 19511956, 2003.

[125] S. D. Anker, W. Doehner, M. Rauchhaus et al., "Uric acid and survival in chronic heart: failure validation and application in metabolic, functional, and hemodynamic staging," Circulation, vol. 107, no. 15, pp. 1991-1997, 2003.

[126] M. E. Suliman, R. J. Johnson, E. García-López et al., "J-shaped mortality relationship for uric acid in CKD," American Journal of Kidney Diseases, vol. 48, no. 5, pp. 761-771, 2006.

[127] S. M. K. Lee, A. L. Lee, T. J. Winters et al., "Low serum uric acid level is a risk factor for death in incident hemodialysis patients," American Journal of Nephrology, vol. 29, no. 2, pp. 79-85, 2009.

[128] Y. Tsuruta, K. Kikuchi, Y. Tsuruta et al., "Febuxostat improves endothelial function in hemodialysis patients with hyperuricemia: a randomized controlled study," Hemodialysis International, vol. 19, no. 4, pp. 514-520, 2015.

[129] S. D. Cohen, P. L. Kimmel, R. Neff, L. Agodoa, and K. C. Abbott, "Association of incident gout and mortality in dialysis patients," Journal of the American Society of Nephrology, vol. 19, no. 11, pp. 2204-2210, 2008.

[130] K. Kohagura, M. Kochi, T. Miyagi et al., "An association between uric acid levels and renal arteriolopathy in chronic kidney disease: a biopsy-based study," Hypertension Research, vol. 36, no. 1, pp. 43-49, 2013.

[131] G. Sturm, B. Kollerits, U. Neyer, E. Ritz, and F. Kronenberg, "Uric acid as a risk factor for progression of non-diabetic chronic kidney disease? The Mild to Moderate Kidney Disease (MMKD) Study," Experimental Gerontology, vol. 43, no. 4, pp. 347-352, 2008.

[132] M. Madero, M. J. Sarnak, X. Wang et al., "Uric acid and longterm outcomes in CKD," American Journal of Kidney Diseases, vol. 53, no. 5, pp. 796-803, 2009.

[133] Y.-P. Siu, K.-T. Leung, M. K.-H. Tong, and T.-H. Kwan, “Use of allopurinol in slowing the progression of renal disease through its ability to lower serum uric acid level," American Journal of Kidney Diseases, vol. 47, no. 1, pp. 51-59, 2006. 
[134] M. Goicoechea, S. G. De Vinuesa, U. Verdalles et al., "Effect of allopurinol in chronic kidney disease progression and cardiovascular risk," Clinical Journal of the American Society of Nephrology, vol. 5, no. 8, pp. 1388-1393, 2010.

[135] M. Goicoechea, S. Garcia de Vinuesa, U. Verdalles et al., "Allopurinol and progression of CKD and cardiovascular events: longterm follow-up of a randomized clinical trial," American Journal of Kidney Diseases, vol. 65, no. 4, pp. 543-549, 2015.

[136] D. Sircar, S. Chatterjee, R. Waikhom et al., "Efficacy of febuxostat for slowing the GFR decline in patients with CKD and asymptomatic hyperuricemia: a 6-month, double-blind, randomized, placebo-controlled trial," American Journal of Kidney Diseases, vol. 66, no. 6, pp. 945-950, 2015.

[137] T. Hosoya, I. Ohno, S. Nomura et al., "Effects of topiroxostat on the serum urate levels and urinary albumin excretion in hyperuricemic stage 3 chronic kidney disease patients with or without gout," Clinical and Experimental Nephrology, vol. 18, no. 6, pp. 876-884, 2014.

[138] R. J. Johnson, T. Nakagawa, D. Jalal, L. G. Sánchez-Lozada, D.H. Kang, and E. Ritz, "Uric acid and chronic kidney disease: which is chasing which?" Nephrology Dialysis Transplantation, vol. 28, no. 9, pp. 2221-2228, 2013.

[139] D. M. Maahs, L. Caramori, D. Z. I. Cherney et al., "Uric acid lowering to prevent kidney function loss in diabetes: the preventing early renal function loss (PERL) Allopurinol Study," Current Diabetes Reports, vol. 13, no. 4, pp. 550-559, 2013.

[140] L. Li, C. Yang, Y. Zhao, X. Zeng, F. Liu, and P. Fu, "Is hyperuricemia an independent risk factor for new-onset chronic kidney disease?: a systematic review and meta-analysis based on observational cohort studies," BMC Nephrology, vol. 15, article $122,2014$.

[141] D. I. Feig, B. Soletsky, and R. J. Johnson, "Effect of allopurinol on blood pressure of adolescents with newly diagnosed essential hypertension: a randomized trial," The Journal of the American Medical Association, vol. 300, no. 8, pp. 924-932, 2008.

[142] M. Madero, F. E. Rodríguez Castellanos, D. Jalal et al., "A pilot study on the impact of a low fructose diet and allopurinol on clinic blood pressure among overweight and prehypertensive subjects: a randomized placebo controlled trial," Journal of the American Society of Hypertension, vol. 9, no. 11, pp. 837-844, 2015.

[143] M. F. Holick, J. E. Frommer, S. C. McNeill, N. M. Richtand, J. W. Henley, and J. T. Potts Jr., "Photometabolism of 7dehydrocholesterol to previtamin $\mathrm{D}_{3}$ in skin," Biochemical and Biophysical Research Communications, vol. 76, no. 1, pp. 107-114, 1977.

[144] J. B. Cheng, M. A. Levine, N. H. Bell, D. J. Mangelsdorf, and D. W. Russell, "Genetic evidence that the human CYP2R1 enzyme is a key vitamin D 25-hydroxylase," Proceedings of the National Academy of Sciences of the United States of America, vol. 101, no. 20, pp. 7711-7715, 2004.

[145] G. K. Fu, D. Lin, M. Y. H. Zhang et al., "Cloning of human 25-hydroxyvitamin D-1 $\alpha$-hydroxylase and mutations causing vitamin D-dependent rickets type 1," Molecular Endocrinology, vol. 11, no. 13, pp. 1961-1970, 1997.

[146] A. S. Dusso, A. J. Brown, and E. Slatopolsky, "Vitamin D," American Journal of Physiology-Renal Physiology, vol. 289, no. 1, pp. F8-F28, 2005.

[147] R. Bouillon, G. Carmeliet, L. Verlinden et al., "Vitamin D and human health: lessons from vitamin D receptor null mice," Endocrine Reviews, vol. 29, no. 6, pp. 726-776, 2008.
[148] E. Kállay, P. Bareis, E. Bajna et al., "Vitamin D receptor activity and prevention of colonic hyperproliferation and oxidative stress," Food and Chemical Toxicology, vol. 40, no. 8, pp. 11911196, 2002.

[149] P. Valcheva, A. Cardus, S. Panizo et al., "Lack of vitamin D receptor causes stress-induced premature senescence in vascular smooth muscle cells through enhanced local angiotensin-II signals," Atherosclerosis, vol. 235, no. 2, pp. 247-255, 2015.

[150] A. Kumar and A. Singh, "A review on mitochondrial restorative mechanism of antioxidants in Alzheimer's disease and other neurological conditions," Frontiers in Pharmacology, vol. 6, p. 206, 2015.

[151] L. Bartik, G. K. Whitfield, M. Kaczmarska et al., "Curcumin: a novel nutritionally derived ligand of the vitamin $\mathrm{D}$ receptor with implications for colon cancer chemoprevention," Journal of Nutritional Biochemistry, vol. 21, no. 12, pp. 1153-1161, 2010.

[152] M. Heger, R. F. van Golen, M. Broekgaarden, and M. C. Michel, "The molecular basis for the pharmacokinetics and pharmacodynamics of curcumin and its metabolites in relation to cancer," Pharmacological Reviews, vol. 66, no. 1, pp. 222-307, 2014.

[153] M. Kuro-o, Y. Matsumura, H. Aizawa et al., "Mutation of the mouse klotho gene leads to a syndrome resembling ageing," Nature, vol. 390, no. 6655, pp. 45-51, 1997.

[154] W. L. Lau, E. M. Leaf, M. C. Hu et al., "Vitamin D receptor agonists increase klotho and osteopontin while decreasing aortic calcification in mice with chronic kidney disease fed a high phosphate diet," Kidney International, vol. 82, no. 12, pp. 1261-1270, 2012.

[155] A. Scholze, Y. Liu, L. Pedersen et al., "Soluble $\alpha$-Klotho and its relation to kidney function and fibroblast growth factor-23," Journal of Clinical Endocrinology and Metabolism, vol. 99, no. 5, pp. E855-E861, 2014.

[156] S. L. Barker, J. Pastor, D. Carranza et al., "The demonstration of $\alpha$ Klotho deficiency in human chronic kidney disease with a novel synthetic antibody," Nephrology Dialysis Transplantation, vol. 30, no. 2, pp. 223-233, 2015.

[157] R. E. Forster, P. W. Jurutka, J.-C. Hsieh et al., "Vitamin D receptor controls expression of the anti-aging klotho gene in mouse and human renal cells," Biochemical and Biophysical Research Communications, vol. 414, no. 3, pp. 557-562, 2011.

[158] P. Ravikumar, J. Ye, J. Zhang et al., " $\alpha$-klotho protects against oxidative damage in pulmonary epithelia," American Journal of Physiology-Lung Cellular and Molecular Physiology, vol. 307, no. 7, pp. L566-L575, 2014.

[159] P. Ravikumar, L. Li, J. Ye et al., " $\alpha$ Klotho deficiency in acute kidney injury contributes to lung damage," Journal of Applied Physiology, vol. 120, no. 7, pp. 723-732, 1985.

[160] B. Rizzo, G. Maltese, M. P. Paraskevi, S. Hrelia, G. Mann, and R. Siow, "Induction of genes by sulforaphane and klotho in human aortic smooth muscle cells," Free Radical Biology \& Medicine, vol. 75, supplement 1, pp. S14-S15, 2014.

[161] M. Kokkinaki, M. Abu-Asab, N. Gunawardena et al., "Klotho regulates retinal pigment epithelial functions and protects against oxidative stress," Journal of Neuroscience, vol. 33, no. 41, pp. 16346-16359, 2013.

[162] M. R. Haussler, G. K. Whitfield, C. A. Haussler et al., "1,25Dihydroxyvitamin D and klotho: a tale of two renal hormones coming of age," Vitamins \& Hormones, vol. 100, pp. 165-230, 2016. 
[163] M. Bhat and A. Ismail, "Vitamin D treatment protects against and reverses oxidative stress induced muscle proteolysis," Journal of Steroid Biochemistry and Molecular Biology, vol. 152, pp. 171-179, 2015.

[164] J. T. R. Keeney, S. Förster, R. Sultana et al., "Dietary vitamin D deficiency in rats from middle to old age leads to elevated tyrosine nitration and proteomics changes in levels of key proteins in brain: implications for low vitamin D-dependent age-related cognitive decline," Free Radical Biology and Medicine, vol. 65, pp. 324-334, 2013.

[165] W. M. Luchi, M. H. M. Shimizu, D. Canale et al., "Vitamin $\mathrm{D}$ deficiency is a potential risk factor for contrast-induced nephropathy," American Journal of Physiology-Regulatory Integrative and Comparative Physiology, vol. 309, no. 3, pp. R215R222, 2015.

[166] J. P. Sales de Almeida, L. S. Liberatti, F. E. Nascimento Barros et al., "Profile of oxidative stress markers is dependent on vitamin D levels in patients with chronic hepatitis C," Nutrition, vol. 32, no. 3, pp. 362-367, 2016.

[167] C. Gordon-Thomson, R. Gupta, W. Tongkao-On, A. Ryan, G. M. Halliday, and R. S. Mason, " $1 \alpha, 25$ Dihydroxyvitamin $\mathrm{D}_{3}$ enhances cellular defences against UV-induced oxidative and other forms of DNA damage in skin," Photochemical and Photobiological Sciences, vol. 11, no. 12, pp. 1837-1847, 2012.

[168] P. Kanikarla-Marie and S. K. Jain, " $1,25(\mathrm{OH})_{2} \mathrm{D}_{3}$ inhibits oxidative stress and monocyte adhesion by mediating the upregulation of GCLC and GSH in endothelial cells treated with acetoacetate (ketosis)," The Journal of Steroid Biochemistry and Molecular Biology, vol. 159, pp. 94-101, 2016.

[169] F. Uberti, D. Lattuada, V. Morsanuto et al., "Vitamin D protects human endothelial cells from oxidative stress through the autophagic and survival pathways," Journal of Clinical Endocrinology and Metabolism, vol. 99, no. 4, pp. 1367-1374, 2014.

[170] J. R. Wu-Wong, M. Nakane, J. Ma, X. Ruan, and P. E. Kroeger, "Elevated phosphorus modulates vitamin D receptor-mediated gene expression in human vascular smooth muscle cells," American Journal of Physiology-Renal Physiology, vol. 293, no. 5, pp. F1592-F1604, 2007.

[171] J. Guo, N. Xia, L. Yang et al., "GSK-3 $\beta$ and vitamin D receptor are involved in $\beta$-catenin and snail signaling in high glucose-induced epithelial-mesenchymal transition of mouse podocytes," Cellular Physiology and Biochemistry, vol. 33, no. 4, pp. 1087-1096, 2014.

[172] X.-L. Zhang, Y.-F. Guo, Z.-X. Song, and M. Zhou, "Vitamin D prevents podocyte injury via regulation of macrophage M1/M2 phenotype in diabetic nephropathy rats," Endocrinology, vol. 155, no. 12, pp. 4939-4950, 2014.

[173] X. Zhang, Z. Song, Y. Guo, and M. Zhou, "The novel role of TRPC6 in vitamin D ameliorating podocyte injury in STZinduced diabetic rats," Molecular and Cellular Biochemistry, vol. 399, no. 1-2, pp. 155-165, 2015.

[174] Z. Song, Y. Guo, M. Zhou, and X. Zhang, "The PI3K/p-Akt signaling pathway participates in calcitriol ameliorating podocyte injury in DN rats," Metabolism: Clinical and Experimental, vol. 63, no. 10, pp. 1324-1333, 2014.

[175] M. Garsen, R. Sonneveld, A. L. Rops et al., "Vitamin D attenuates proteinuria by inhibition of heparanase expression in the podocyte," Journal of Pathology, vol. 237, no. 4, pp. 472-481, 2016.
[176] J. Ma, B. Zhang, S. Liu et al., "1,25-dihydroxyvitamin $\mathrm{D}_{3}$ inhibits podocyte uPAR expression and reduces proteinuria," PLoS ONE, vol. 8, no. 5, article e64912, 2013.

[177] P. Rai, T. Singh, R. Lederman et al., "Hyperglycemia enhances kidney cell injury in HIVAN through down-regulation of vitamin D receptors," Cellular Signalling, vol. 27, no. 3, pp. 460469, 2015.

[178] K. Husain, L. Ferder, M. Mizobuchi, J. Finch, and E. Slatopolsky, "Combination therapy with paricalcitol and enalapril ameliorates cardiac oxidative injury in uremic rats," American Journal of Nephrology, vol. 29, no. 5, pp. 465-472, 2009.

[179] J. L. Finch, E. B. Suarez, K. Husain et al., "Effect of combining an ACE inhibitor and a VDR activator on glomerulosclerosis, proteinuria, and renal oxidative stress in uremic rats," American Journal of Physiology - Renal Physiology, vol. 302, no. 1, pp. 141149, 2012.

[180] X. X. Wang, T. Jiang, Y. Shen et al., "Vitamin D receptor agonist doxercalciferol modulates dietary fat-induced renal disease and renal lipid metabolism," American Journal of Physiology: Renal Physiology, vol. 300, no. 3, pp. F801-F810, 2011.

[181] M. J. Izquierdo, M. Cavia, P. Muñiz et al., "Paricalcitol reduces oxidative stress and inflammation in hemodialysis patients," BMC Nephrology, vol. 13, article 159, 2012.

[182] T. K. Thethi, M. A. Bajwa, H. Ghanim et al., "Effect of paricalcitol on endothelial function and inflammation in type 2 diabetes and chronic kidney disease," Journal of Diabetes and its Complications, vol. 29, no. 3, pp. 433-437, 2015.

[183] J. G. Heaf, P. Joffe, and P. Marckmann, "Vitamin D and stage 5 chronic kidney disease: a new paradigm?" Seminars in Dialysis, vol. 25, no. 1, pp. 50-58, 2012.

[184] P. Marckmann, H. Agerskov, S. Thineshkumar et al., "Randomized controlled trial of cholecalciferol supplementation in chronic kidney disease patients with hypovitaminosis D," Nephrology Dialysis Transplantation, vol. 27, no. 9, pp. 35233531, 2012.

[185] E. Seibert, G. H. Heine, C. Ulrich, S. Seiler, H. Köhler, and M. Girndt, "Influence of cholecalciferol supplementation in hemodialysis patients on monocyte subsets: a randomized, double-blind, placebo-controlled clinical trial," NephronClinical Practice, vol. 123, no. 3-4, pp. 209-219, 2013.

[186] J. R. Stubbs, A. Idiculla, J. Slusser, R. Menard, and L. D. Quarles, "Cholecalciferol supplementation alters calcitriol-responsive monocyte proteins and decreases inflammatory cytokines in ESRD," Journal of the American Society of Nephrology, vol. 21, no. 2, pp. 353-361, 2010.

[187] P. J. Matias, C. Jorge, C. Ferreira et al., "Cholecalciferol supplementation in hemodialysis patients: effects on mineral metabolism, inflammation, and cardiac dimension parameters," Clinical Journal of the American Society of Nephrology, vol. 5, no. 5, pp. 905-911, 2010.

[188] S. Bucharles, S. H. Barberato, A. E. M. Stinghen et al., "Impact of cholecalciferol treatment on biomarkers of inflammation and myocardial structure in hemodialysis patients without hyperparathyroidism," Journal of Renal Nutrition, vol. 22, no. 2, pp. 284-291, 2012.

[189] J. A. Alvarez, S. M. Zughaier, J. Law et al., "Effects of high-dose cholecalciferol on serum markers of inflammation and immunity in patients with early chronic kidney disease," European Journal of Clinical Nutrition, vol. 67, no. 3, pp. 264-269, 2013.

[190] M. J. Kim, A. H. Frankel, M. Donaldson et al., "Oral cholecalciferol decreases albuminuria and urinary TGF- $\beta 1$ in patients with 
type 2 diabetic nephropathy on established renin-angiotensinaldosterone system inhibition," Kidney International, vol. 80, no. 8, pp. 851-860, 2011.

[191] A. S. Dusso and M. Tokumoto, "Defective renal maintenance of the vitamin D endocrine system impairs vitamin D renoprotection: a downward spiral in kidney disease," Kidney International, vol. 79, no. 7, pp. 715-729, 2011.

[192] A. S. Dusso, "Renal vitamin D receptor expression and vitamin D renoprotection," Kidney International, vol. 81, no. 10, pp. 937939, 2012.

[193] M. Kuroda, Y. Mimaki, T. Nishiyama et al., "Hypoglycemic effects of turmeric (Curcuma longa L. rhizomes) on genetically diabetic KK-Ay mice," Biological and Pharmaceutical Bulletin, vol. 28, no. 5, pp. 937-939, 2005.

[194] B. M. Brenner, M. E. Cooper, D. de Zeeuw et al., "Effects of losartan on renal and cardiovascular outcomes in patients with type 2 diabetes and nephropathy," The New England Journal of Medicine, vol. 345, no. 12, pp. 861-869, 2001.

[195] B. Satirapoj, "Review on pathophysiology and treatment of diabetic kidney disease," Journal of the Medical Association of Thailand, vol. 93, supplement 6, pp. S228-S241, 2010.

[196] A. S. Arellano-Buendía, F. E. García-Arroyo, M. CristóbalGarcía et al., "Urinary excretion of neutrophil gelatinaseassociated lipocalin in diabetic rats," Oxidative Medicine and Cellular Longevity, vol. 2014, Article ID 961326, 11 pages, 2014.

[197] A. S. Arellano-Buendía, M. Tostado-González, F. E. GarcíaArroyo et al., "Anti-inflammatory therapy modulates Nrf2keapl in kidney from rats with diabetes," Oxidative Medicine and Cellular Longevity, vol. 2016, Article ID 4693801, 11 pages, 2016.

[198] R. A. DeFronzo, J. A. Davidson, and S. del Prato, "The role of the kidneys in glucose homeostasis: a new path towards normalizing glycaemia," Diabetes, Obesity and Metabolism, vol. 14, no. 1, pp. 5-14, 2012.

[199] J. Ditzel, H.-H. Lervang, and J. Brochner-Mortensen, "Renal sodium metabolism in relation to hypertension in diabetes," Diabete et Metabolisme, vol. 15, no. 5, pp. 292-295, 1989.

[200] J. C. Mbanya, T. H. Thomas, R. Taylor, K. G. M. M. Alberti, and R. Wilkinson, "Increased proximal tubular sodium reabsorption in hypertensive patients with Type 2 diabetes," Diabetic Medicine, vol. 6, no. 7, pp. 614-620, 1989.

[201] H. Rahmoune, P. W. Thompson, J. M. Ward, C. D. Smith, G. Hong, and J. Brown, "Glucose transporters in human renal proximal tubular cells isolated from the urine of patients with non-insulin-dependent diabetes," Diabetes, vol. 54, no. 12, pp. 3427-3434, 2005.

[202] H. Osorio, R. Bautista, A. Rios et al., "Effect of phlorizin on SGLT2 expression in the kidney of diabetic rats," Journal of Nephrology, vol. 23, no. 5, pp. 541-546, 2010.

[203] H. Osorio, I. Coronel, A. Arellano et al., "Sodium-glucose cotransporter inhibition prevents oxidative stress in the kidney of diabetic rats," Oxidative Medicine and Cellular Longevity, vol. 2012, Article ID 542042, 7 pages, 2012.

[204] H. Osorio, I. Coronel, A. Arellano, M. Franco, B. Escalante, and R. Bautista, "Ursodeoxycholic acid decreases sodium-glucose cotransporter (SGLT2) expression and oxidative stress in the kidney of diabetic rats," Diabetes Research and Clinical Practice, vol. 97, no. 2, pp. 276-282, 2012.

[205] H. S. Freitas, G. F. Anhê, K. F. S. Melo et al., "Na ${ }^{+}$-glucose transporter-2 messenger ribonucleic acid expression in kidney of diabetic rats correlates with glycemic levels: involvement of hepatocyte nuclear factor- $1 \alpha$ expression and activity," Endocrinology, vol. 149, no. 2, pp. 717-724, 2008.
[206] N. M. Tabatabai, M. Sharma, S. S. Blumenthal, and D. H. Petering, "Enhanced expressions of sodium-glucose cotransporters in the kidneys of diabetic Zucker rats," Diabetes Research and Clinical Practice, vol. 83, no. 1, pp. e27-e30, 2009.

[207] D. Z. I. Cherney, B. A. Perkins, N. Soleymanlou et al., "Renal hemodynamic effect of sodium-glucose cotransporter 2 inhibition in patients with type 1 diabetes mellitus," Circulation, vol. 129, no. 5, pp. 587-597, 2014.

[208] B. Peene and K. Benhalima, "Sodium glucose transporter protein 2 inhibitors: focusing on the kidney to treat type 2 diabetes," Therapeutic Advances in Endocrinology and Metabolism, vol. 5, no. 5, pp. 124-136, 2014.

[209] R. V. Oliva and G. L. Bakris, "Blood pressure effects of sodiumglucose co-transport 2 (SGLT2) inhibitors," Journal of the American Society of Hypertension, vol. 8, no. 5, pp. 330-339, 2014.

[210] A. Tahara, E. Kurosaki, M. Yokono et al., "Effects of SGLT2 selective inhibitor ipragliflozin on hyperglycemia, hyperlipidemia, hepatic steatosis, oxidative stress, inflammation, and obesity in type 2 diabetic mice," European Journal of Pharmacology, vol. 715, no. 1-3, pp. 246-255, 2013.

[211] G. Khalaf, "A histological study on the possible protective role of garlic in diabetes-induced structural changes in the renal cortex of adult male albino rats," Egyptian Journal of Histology, vol. 35, no. 4, pp. 812-821, 2012.

[212] M. Thomson, K. K. Al-Qattan, J. S. Divya, and M. Ali, "Antidiabetic and anti-oxidant potential of aged garlic extract (AGE) in streptozotocin-induced diabetic rats," BMC Complementary and Alternative Medicine, vol. 16, article 17, 2016.

[213] T. M. Shiju, R. Rajkumar, N. G. Rajesh, and P. Viswanathan, "Aqueous extract of Allium sativum L bulbs offer nephroprotection by attenuating vascular endothelial growth factor and extracellular signal-regulated kinase-1 expression in diabetic rats," Indian Journal of Experimental Biology, vol. 51, no. 2, pp. 139-148, 2013.

[214] K. K. Al-Qattan, M. H. Mansour, M. Thomson, and M. Ali, "Garlic decreases liver and kidney receptor for advanced glycation end products expression in experimental diabetes," Pathophysiology, vol. 23, no. 2, pp. 135-145, 2016.

[215] K. K. Al-Qattan, M. Thomson, M. Ali, and M. H. Mansour, "Garlic (Allium sativum) attenuate glomerular glycation in streptozotocin-induced diabetic rats: a possible role of insulin," Pathophysiology, vol. 20, no. 2, pp. 147-152, 2013.

[216] S. Dhanarasu, "Evaluation of ameliorative effect of allicin (diallyl thiosulfinate) on experimentally induced diabetes mellitus in albino rats," Egyptian Academic Journal of Biological Sciences, vol. 7, pp. 1-10, 2015.

[217] G. Saravanan and P. Ponmurugan, "Ameliorative potential of Sallyl cysteine on oxidative stress in STZ induced diabetic rats," Chemico-Biological Interactions, vol. 189, no. 1-2, pp. 100-106, 2011.

[218] M. H. Mansour, K. Al-Qattan, M. Thomson, and M. Ali, "Garlic (Allium sativum) down-regulates the expression of angiotensin II $\mathrm{AT}_{1}$ receptor in adrenal and renal tissues of streptozotocininduced diabetic rats," Inflammopharmacology, vol. 21, no. 2, pp. 147-159, 2013.

[219] K. Balamash, O. Albar, Q. Wang, and N. Ahmed, "Effect of Kyolic ${ }^{\circledR}$ aged garlic extract on glycaemia, lipidaemia and oxidative stress in patients with type 2 diabetes mellitus," Journal of Diabetes Research and Clinical Metabolism, vol. 1, article 9, 2012. 
[220] A. K. Sheikhi, T. Ghazanfari, M. Jafar-Rangchi et al., "Effects of garlic (Allium sativum) extract on the expression of receptor for advanced glycation end products and proinflammatory cytokines secretion in peripheral blood mononuclear cells from patients with type 2 diabetes mellitus," Archives of Medical Laboratory Sciences, vol. 1, no. 1, 2015.

[221] I. Durak, M. Kavutcu, B. Aytaç et al., "Effects of garlic extract consumption on blood lipid and oxidant/antioxidant parameters in humans with high blood cholesterol," Journal of Nutritional Biochemistry, vol. 15, no. 6, pp. 373-377, 2004.

[222] S. Sharma, S. K. Kulkarni, and K. Chopra, "Curcumin, the active principle of turmeric (Curcuma longa), ameliorates diabetic nephropathy in rats," Clinical and Experimental Pharmacology and Physiology, vol. 33, no. 10, pp. 940-945, 2006.

[223] J. Chiu, Z. A. Khan, H. Farhangkhoee, and S. Chakrabarti, "Curcumin prevents diabetes-associated abnormalities in the kidneys by inhibiting p300 and nuclear factor- $\kappa$ B," Nutrition, vol. 25, no. 9, pp. 964-972, 2009.

[224] E. S. H. Abd Allah and A. M. S. Gomaa, "Effects of curcumin and captopril on the functions of kidney and nerve in streptozotocin-induced diabetic rats: role of angiotensin converting enzyme 1," Applied Physiology, Nutrition and Metabolism, vol. 40, no. 10, pp. 1061-1067, 2015.

[225] S. K. Jain, J. Rains, J. Croad, B. Larson, and K. Jones, "Curcumin supplementation lowers TNF- $\alpha$, IL-6, IL-8, and MCP1 secretion in high glucose-treated cultured monocytes and blood levels of TNF- $\alpha$, IL-6, MCP-1, glucose, and glycosylated hemoglobin in diabetic rats," Antioxidants and Redox Signaling, vol. 11, no. 2, pp. 241-249, 2009.

[226] L.-N. Sun, X.-C. Liu, X.-J. Chen, G.-J. Guan, and G. Liu, "Curcumin attenuates high glucose-induced podocyte apoptosis by regulating functional connections between caveolin-1 phosphorylation and ROS," Acta Pharmacologica Sinica, vol. 37, no. 5, pp. 645-655, 2016.

[227] Z. S. Ibrahim, M. E. Alkafafy, M. M. Ahmed, and M. M. Soliman, "Renoprotective effect of curcumin against the combined oxidative stress of diabetes and nicotine in rats," Molecular Medicine Reports, vol. 13, no. 4, pp. 3017-3026, 2016.

[228] S. Ganjali, A. Sahebkar, E. Mahdipour et al., "Investigation of the effects of curcumin on serum cytokines in obese individuals: a randomized controlled trial," The Scientific World Journal, vol. 2014, Article ID 898361, 6 pages, 2014.

[229] P. Khajehdehi, M. Pakfetrat, K. Javidnia et al., "Oral supplementation of turmeric attenuates proteinuria, transforming growth factor- $\beta$ and interleukin- 8 levels in patients with overt type 2 diabetic nephropathy: a randomized, double-blind and placebo-controlled study,' Scandinavian Journal of Urology and Nephrology, vol. 45, no. 5, pp. 365-370, 2011.

[230] S. Chuengsamarn, S. Rattanamongkolgul, R. Luechapudiporn, C. Phisalaphong, and S. Jirawatnotai, "Curcumin extract for prevention of type 2 diabetes," Diabetes Care, vol. 35, no. 11, pp. 2121-2127, 2012.

[231] A. S. Jiménez-Osorio, W. R. García-Niño, S. González-Reyes et al., "The effect of dietary supplementation with curcumin on redox status and Nrf2 activation in patients with nondiabetic or diabetic proteinuric chronic kidney disease: A Pilot Study," Journal of Renal Nutrition, 2016.

[232] E. Y. Sukandar, H. Permana, I. K. Adnyana et al., "Clinical study of turmeric (Curcuma longa L.) and Garlic (Allium sativum L.) extracts as antihyperglycemic and antihyperlipidemic agent in type-2 diabetes-dyslipidemia patients," International Journal of Pharmacology, vol. 6, no. 4, pp. 456-463, 2010.
[233] C. Ho, Y.-C. Hsu, C.-C. Lei, S.-C. Mau, Y.-H. Shih, and C.L. Lin, "Curcumin rescues diabetic renal fibrosis by targeting superoxide-mediated Wnt signaling pathways," The American Journal of the Medical Sciences, vol. 351, no. 3, pp. 286-295, 2016.

[234] V. Soetikno, K. Watanabe, F. R. Sari et al., "Curcumin attenuates diabetic nephropathy by inhibiting PKC- $\alpha$ and PKC- $\beta 1$ activity in streptozotocin-induced type I diabetic rats," Molecular Nutrition and Food Research, vol. 55, no. 11, pp. 1655-1665, 2011.

[235] A. L. Al-Malki and H. A. El Rabey, "The antidiabetic effect of low doses of Moringa oleifera Lam. seeds on streptozotocin induced diabetes and diabetic nephropathy in male rats," BioMed Research International, vol. 2015, Article ID 381040, 13 pages, 2015.

[236] R. Gupta, M. Mathur, V. K. Bajaj et al., "Evaluation of antidiabetic and antioxidant activity of Moringa oleifera in experimental diabetes," Journal of Diabetes, vol. 4, no. 2, pp. 164171, 2012.

[237] M. G. Rajanandh, M. N. Satishkumar, K. Elango, and B. Suresh, "Moringa oleifera Lam. A herbal medicine for hyperlipidemia: a pre-clinical report," Asian Pacific Journal of Tropical Disease, vol. 2, supplement 2, pp. S790-S795, 2012.

[238] D. Jaiswal, P. K. Rai, S. Mehta et al., "Role of Moringa oleifera in regulation of diabetes-induced oxidative stress," Asian Pacific Journal of Tropical Medicine, vol. 6, no. 6, pp. 426-432, 2013.

[239] E. B. Oyewo, E. G. Adeleke, B. P. Fakunle, and M. O. Iniaghe, "Blood glucose and lipid reducing activities of the oral administration of aqueous leaf extract of Moringa oleifera in Wistar rats," Journal of Natural Sciences Research, vol. 3, no. 6, pp. 9299, 2013.

[240] Ples M, H.H. Comparative effects of Moringa Oleifera Lam te on normal and hyperglycemic patients. eHealth Int J. http://ehealthinternational.org/.

[241] D. J. Kumari, "Hypoglycemic effect of Moringa oleifera and Azadirachta indica in type-2 diabetes," Bioscan, vol. 5, pp. 211214, 2010.

[242] V. V. A. Ghiridhari, D. Malhati, and K. Geetha, "Anti-diabetic properties of drumstick (Moringa oleifera) leaf tablets," International Journal of Health and Nutrition, vol. 2, pp. 1-5, 2011.

[243] S. Kushwaha, P. Chawla, and A. Kochhar, "Effect of supplementation of drumstick (Moringa oleifera) and amaranth (Amaranthus tricolor) leaves powder on antioxidant profile and oxidative status among postmenopausal women," Journal of Food Science and Technology, vol. 51, no. 11, pp. 3464-3469, 2012.

[244] M. Shalaby and H. Saifan, "Some pharmacological effects of cinnamon and ginger herbs in obese diabetic rats," Journal of Intercultural Ethnopharmacology, vol. 3, no. 4, pp. 144-149, 2014.

[245] A. Mishra, R. Bhatti, A. Singh, and M. P. Singh Ishar, "Ameliorative effect of the cinnamon oil from Cinnamomum zeylanicum upon early stage diabetic nephropathy," Planta Medica, vol. 76, no. 5, pp. 412-417, 2010.

[246] R. Kumar, A. Iqubal, A. Kumar-Singh et al., "Hypoglycemic and nephroprotective effect of cinamomum cassia on alloxan induced diabetic mice," International Journal of Diabetes Research, vol. 3, pp. 36-40, 2014.

[247] P. Muthenna, G. Raghu, P. A. Kumar, M. V. Surekha, and G. B. Reddy, "Effect of cinnamon and its procyanidin-B2 enriched fraction on diabetic nephropathy in rats," Chemico-Biological Interactions, vol. 222, pp. 68-76, 2014.

[248] B. Mang, M. Wolters, B. Schmitt et al., "Effects of a cinnamon extract on plasma glucose, $\mathrm{HbA}_{1 \mathrm{c}}$, and serum lipids in diabetes mellitus type 2," European Journal of Clinical Investigation, vol. 36, no. 5, pp. 340-344, 2006. 
[249] A. S. Sahib, "Antidiabetic and antioxidant effect of cinnamon in poorly controlled type- 2 diabetic iraqi patients: a randomized, placebo-controlled clinical trial," Journal of Intercultural Ethnopharmacology, vol. 5, no. 2, pp. 108-113, 2016.

[250] T. Lu, H. Sheng, J. Wu, Y. Cheng, J. Zhu, and Y. Chen, "Cinnamon extract improves fasting blood glucose and glycosylated hemoglobin level in Chinese patients with type 2 diabetes," Nutrition Research, vol. 32, no. 6, pp. 408-412, 2012.

[251] H. Cao, M. M. Polansky, and R. A. Anderson, "Cinnamon extract and polyphenols affect the expression of tristetraprolin, insulin receptor, and glucose transporter 4 in mouse 3T3-L1 adipocytes," Archives of Biochemistry and Biophysics, vol. 459, no. 2, pp. 214-222, 2007.

[252] X. Sheng, Y. Zhang, Z. Gong, C. Huang, and Y. Q. Zang, "Improved insulin resistance and lipid metabolism by cinnamon extract through activation of peroxisome proliferatoractivated receptors," PPAR Research, vol. 2008, Article ID 581348, 2008.

[253] C. C. Chang, C. Y. Chang, Y. T. Wu, J. P. Huang, T. H. Yen, and L. M. Hung, "Resveratrol retards progression of diabetic nephropathy through modulations of oxidative stress, proinflammatory cytokines, and AMP-activated protein kinase," Journal of Biomedical Science, vol. 18, article 47, 2011.

[254] M. Kitada, S. Kume, N. Imaizumi, and D. Koya, "Resveratrol improves oxidative stress and protects against diabetic nephropathy through normalization of Mn-SOD dysfunction in AMPK/SIRT1-independent pathway," Diabetes, vol. 60, no. 2, pp. 634-643, 2011.

[255] L. Zhang, S. Pang, B. Deng et al., "High glucose induces renal mesangial cell proliferation and fibronectin expression through JNK/NF- $\kappa \mathrm{B} / \mathrm{NADPH}$ oxidase/ROS pathway, which is inhibited by resveratrol," International Journal of Biochemistry and Cell Biology, vol. 44, no. 4, pp. 629-638, 2012.

[256] M. Y. Kim, J. H. Lim, H. H. Youn et al., "Resveratrol prevents renal lipotoxicity and inhibits mesangial cell glucotoxicity in a manner dependent on the AMPK-SIRT1-PGC1 $\alpha$ axis in $\mathrm{db} / \mathrm{db}$ mice," Diabetologia, vol. 56, no. 1, pp. 204-217, 2013.

[257] P. Palsamy and S. Subramanian, "Resveratrol protects diabetic kidney by attenuating hyperglycemia-mediated oxidative stress and renal inflammatory cytokines via Nrf2-Keap1 signaling," Biochimica et Biophysica Acta-Molecular Basis of Disease, vol. 1812, no. 7, pp. 719-731, 2011.

[258] D. Wen, X. Huang, M. Zhang et al., "Resveratrol attenuates diabetic nephropathy via modulating angiogenesis," PLoS ONE, vol. 8, no. 12, Article ID e82336, 2013.

[259] A. Movahed, I. Nabipour, X. Lieben Louis et al., "Antihyperglycemic effects of short term resveratrol supplementation in type 2 diabetic patients," Evidence-Based Complementary and Alternative Medicine, vol. 2013, Article ID 851267, 11 pages, 2013.

[260] J. K. Bhatt, S. Thomas, and M. J. Nanjan, "Resveratrol supplementation improves glycemic control in type 2 diabetes mellitus," Nutrition Research, vol. 32, no. 7, pp. 537-541, 2012.

[261] F. Xu, Y. Wang, W. Cui et al., "Resveratrol prevention of diabetic nephropathy is associated with the suppression of renal inflammation and mesangial cell proliferation: possible roles of Akt/NF- $\kappa$ B pathway," International Journal of Endocrinology, vol. 2014, Article ID 289327, 9 pages, 2014.

[262] G. Shang, X. Tang, P. Gao et al., "Sulforaphane attenuation of experimental diabetic nephropathy involves GSK-3 beta/Fyn/Nrf2 signaling pathway," Journal of Nutritional Biochemistry, vol. 26, no. 6, pp. 596-606, 2015.
[263] W. Cui, Y. Bai, X. Miao et al., "Prevention of diabetic nephropathy by sulforaphane: possible role of Nrf2 upregulation and activation," Oxidative Medicine and Cellular Longevity, vol. 2012, Article ID 821936, 12 pages, 2012.

[264] Z. Bahadoran, P. Mirmiran, F. Hosseinpanah, M. Hedayati, S. Hosseinpour-Niazi, and F. Azizi, "Broccoli sprouts reduce oxidative stress in type 2 diabetes: a randomized double-blind clinical trial," European Journal of Clinical Nutrition, vol. 65, no. 8, pp. 972-977, 2011.

[265] H. Zheng, S. A. Whitman, W. Wu et al., "Therapeutic potential of Nrf2 activators in streptozotocin-induced diabetic nephropathy," Diabetes, vol. 60, no. 11, pp. 3055-3066, 2011.

[266] H. Yamout, V. Perkovic, M. Davies et al., "Efficacy and safety of canagliflozin in patients with type 2 diabetes and stage 3 nephropathy," American Journal of Nephrology, vol. 40, no. 1, pp. 64-74, 2014.

[267] J.-F. Yale, G. Bakris, B. Cariou et al., "Efficacy and safety of canagliflozin over 52 weeks in patients with type 2 diabetes mellitus and chronic kidney disease," Diabetes, Obesity and Metabolism, vol. 16, no. 10, pp. 1016-1027, 2014.

[268] D. E. Kohan, P. Fioretto, W. Tang, and J. F. List, "Long-term study of patients with type 2 diabetes and moderate renal impairment shows that dapagliflozin reduces weight and blood pressure but does not improve glycemic control," Kidney International, vol. 85, no. 4, pp. 962-971, 2014.

[269] J. P. Wilding, V. Woo, N. G. Soler et al., "Long-term efficacy of dapagliflozin in patients with type 2 diabetes mellitus receiving high doses of insulin: a randomized trial," Annals of Internal Medicine, vol. 156, no. 6, pp. 405-415, 2012.

[270] H. J. Lambers Heerspink, D. De Zeeuw, L. Wie, B. Leslie, and J. List, "Dapagliflozin a glucose-regulating drug with diuretic properties in subjects with type 2 diabetes," Diabetes, Obesity and Metabolism, vol. 15, no. 9, pp. 853-862, 2013.

[271] M. A. Weber, T. A. Mansfield, V. A. Cain, N. Iqbal, S. Parikh, and A. Ptaszynska, "Blood pressure and glycaemic effects of dapagliflozin versus placebo in patients with type 2 diabetes on combination antihypertensive therapy: a randomised, doubleblind, placebo-controlled, phase 3 study," The Lancet Diabetes \& Endocrinology, vol. 4, no. 3, pp. 211-220, 2016.

[272] H. J. Heerspink, E. Johnsson, I. Gause-Nilsson, K. Johannson, and C. D. Sjostrom, "Dapagliflozin reduces albuminuria on top of renin-angiotensin system blockade in hypertensive diabetic patients," Diabetes, vol. 64, p. A303, 2015.

[273] H.-U. Häring, L. Merker, E. Seewaldt-Becker et al., "Empagliflozin as add-on to metformin in patients with type 2 diabetes: a 24-week, randomized, double-blind, placebo-controlled trial," Diabetes Care, vol. 37, no. 6, pp. 1650-1659, 2014.

[274] D. Fitchett, B. Zinman, C. Wanner et al., "Heart failure outcomes with empagliflozin in patients with type 2 diabetes at high cardiovascular risk: results of the EMPA-REG OUTCOME$^{\circledR}$ trial," European Heart Journal, vol. 37, no. 19, pp. 15261534, 2016.

[275] B. Zinman, C. Wanner, J. M. Lachin et al., "Empagliflozin, cardiovascular outcomes, and mortality in type 2 diabetes," The New England Journal of Medicine, vol. 373, no. 22, pp. 2117-2128, 2015.

[276] A. Kashiwagi, H. Takahashi, H. Ishikawa et al., "A randomized, double-blind, placebo-controlled study on long-term efficacy and safety of ipragliflozin treatment in patients with type 2 diabetes mellitus and renal impairment: results of the Long-Term ASP1941 Safety Evaluation in Patients with Type 2 Diabetes with 
Renal Impairment (LANTERN) study," Diabetes, Obesity and Metabolism, vol. 17, no. 2, pp. 152-160, 2015.

[277] T. Iizuka, K. Iemitsu, M. Takihata et al., "Efficacy and safety of ipragliflozin in Japanese patients with type 2 diabetes: interim outcome of the ASSIGN-K study," Journal of Clinical Medicine Research, vol. 8, no. 2, pp. 116-125, 2016.

[278] E. Kutoh, A. Wada, T. Murayama, and M. Hirate, "Ipragliflozin as an initial therapy in drug naïve subjects with type 2 diabetes," Drug Research, 2016. 


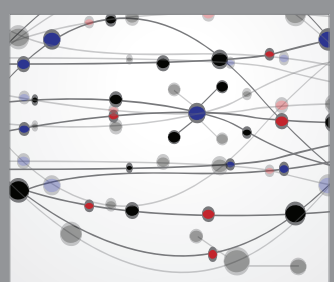

The Scientific World Journal
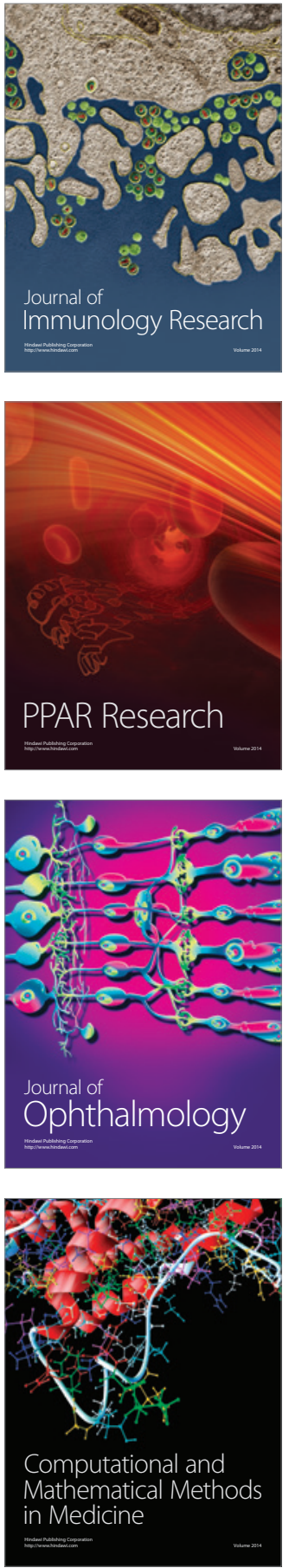

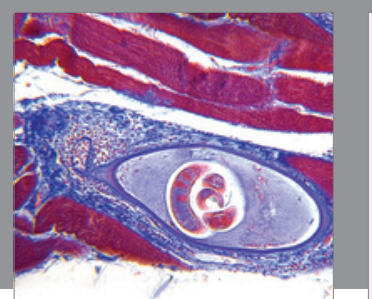

Gastroenterology Research and Practice

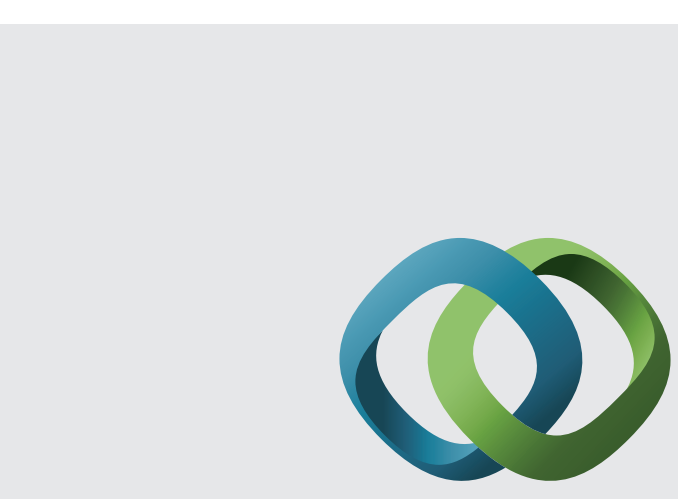

\section{Hindawi}

Submit your manuscripts at

http://www.hindawi.com
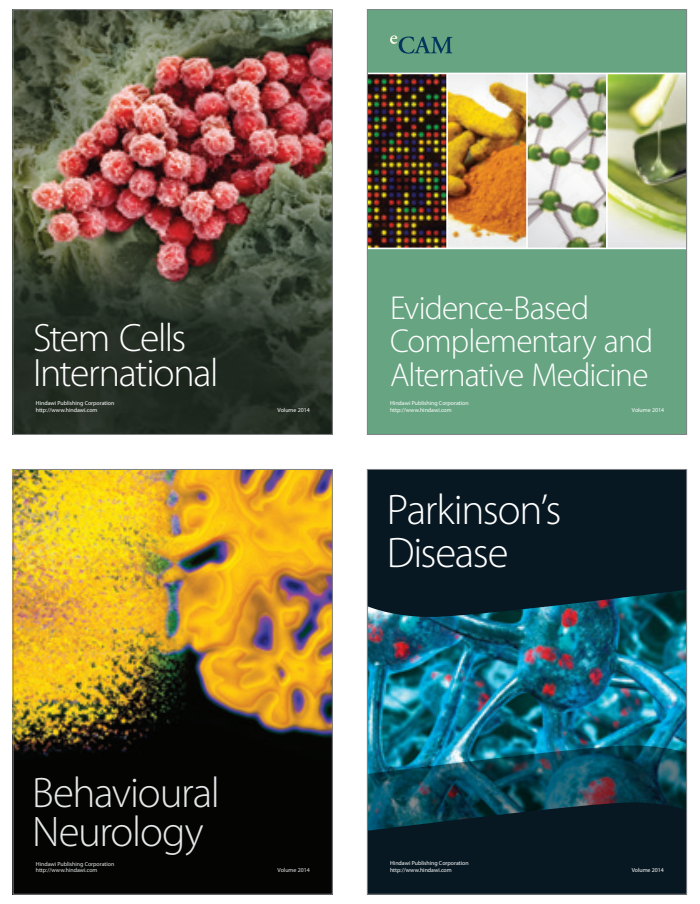
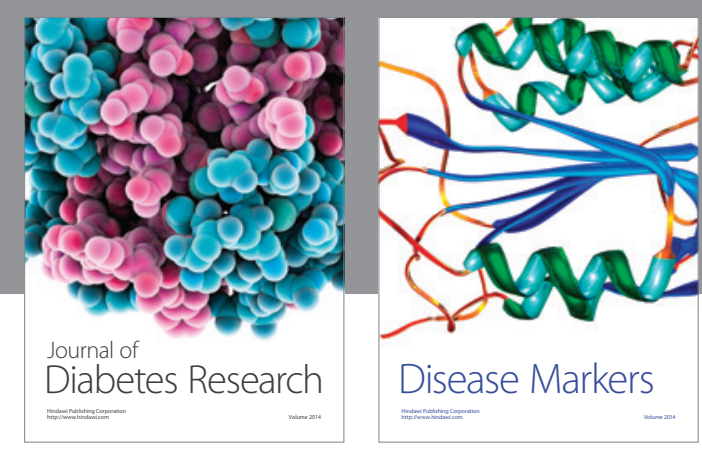

Disease Markers
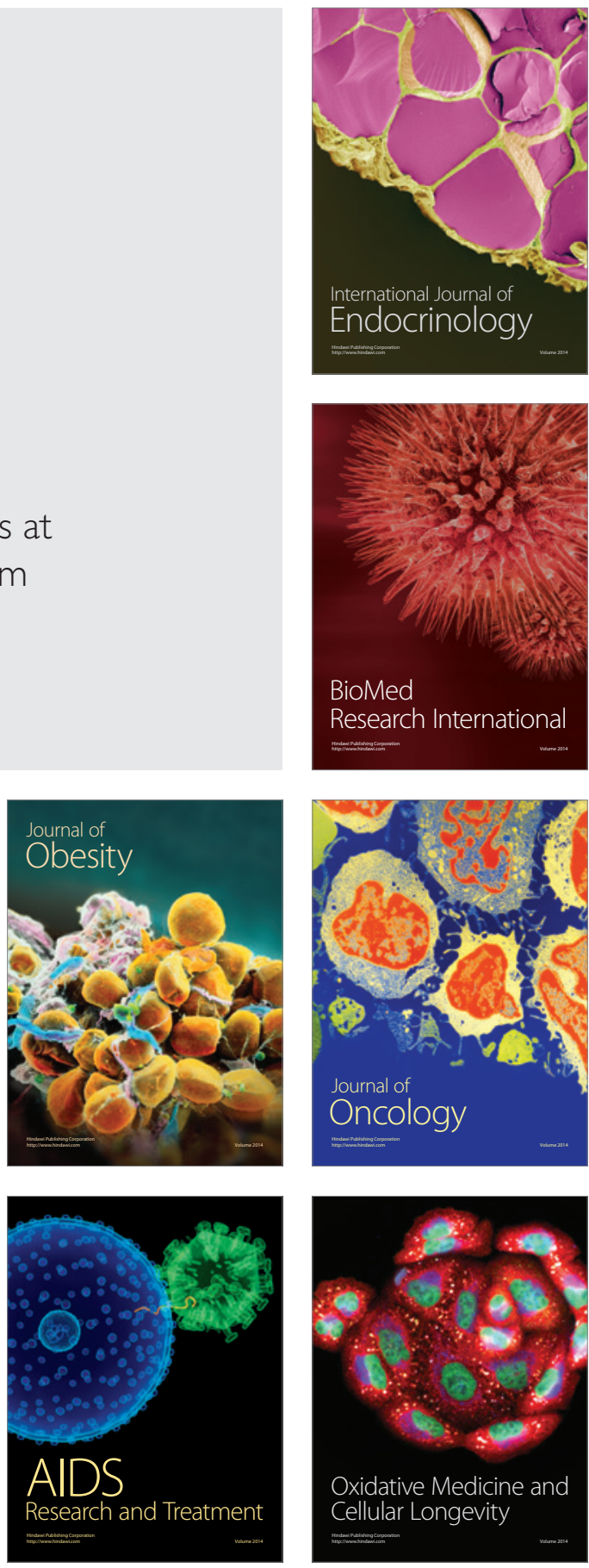